\title{
Review of recent developments in manufacturing lightweight multi-metal gears
}

\author{
Denis J. Politis ${ }^{1}$ Nicholas J. Politis ${ }^{2}$ Jianguo Lin ${ }^{2}$
}

Received: 18 August 2020 / Accepted: 7 December 2020 / Published online: 6 January 2021

(c) The Author(s) 2021

\begin{abstract}
This paper provides a review of recent developments in the manufacturing of lightweight multi-metal components, and in particular gears. The literature has shown that significant efforts have been made in manufacturing light gears and numerous technical challenges exist when designing for and manufacturing with dissimilar metals including challenges in heating technologies, mechanical performance, processing parameters, metal compatibility and the interface layer between adjacent materials, as well as difficulties in multi-metal simulations. Whilst the scope of multi-metal manufacturing is vast, the main concentration of this study is on the main stages of multi-metal gear production, and specifically on preform production, multi-metal heating, intermetallic bonding, and modelling of essential forming parameters. The effects of each of these methods as well as the numerous approaches studied in the literature are presented, with a recommendation being made as to a processing route that may lead to a robust multi-metal gear with minimal production line modifications to conventional steel gears.
\end{abstract}

Keywords Net shape forging $\cdot$ Gears forging $\cdot$ Multi-metal lightweight gears $\cdot$ Billet design $\cdot$ Interface bonding

\section{Introduction}

The transportation sector has continued to be subject to a broad range of constraints in recent years with severe market competition, stringent consumer demands on option customisation, sustainability and quality as well as legislative challenges. Moreover, all these challenges must be faced with a reduced development budget and competitive sales price. Manufacturers have aimed to undertake these challenges by forming partnerships including consolidating chassis and engine applications across model ranges [42], engaging in mergers and joint platform development [155]. Moreover, advances in alternative drive system technologies such as hybrid and all electric vehicles have gained increased acceptance as viable emission reduction systems [162] accompanied with numerous government incentives [157]. Whilst this avenue offers promising solutions to air quality in major

Denis J. Politis

politis.denis@ucy.ac.cy

1 Department of Mechanical and Manufacturing Engineering, University of Cyprus, 1678 Nicosia, Cyprus

2 Department of Mechanical Engineering, Imperial College London, Exhibition Road, London SW7 2AZ, UK cities, there remain significant technical challenges in terms of battery technology, energy storage density, rate of charge and cost of implementation [29].

To date, one of the most proven and effective methods to reduce emissions, which can be implemented across all vehicle propulsion methods including electric vehicles, is the reduction of vehicular weight, through the use of lightweight design technologies. Light structural designs involve the use of lightweight material substitution and novel structure design thus enabling significant savings. This has been effectively implemented in the automotive industry with the Range Rover models, having achieved a $400 \mathrm{~kg}$ weight reduction, largely through the substitution of steel by aluminium in recent models [69]. The impact of weight savings on fuel consumption is significant, with a $10 \%$ reduction in vehicle weight improving fuel efficiency by $6-8 \%$ [72].

Material substitution in non-structural components has been performed for decades. For example, cast iron and steel have been viably replaced with aluminium for engine blocks [129], for vehicle structural members [30] and aluminium or magnesium for gearbox casings [127]. In addition, materials such as carbon-fibres have been used as a replacement for skin panels and structures [2], although their labour intensive production and cost limits application to only the upper 
segment of vehicles. However, with the potential for lightweighting of simple structures being exhausted, industry and academia have begun to focus on the lightweighting of high performance mechanical components such as crankshafts, camshafts and gears. This is particularly challenging as these components are manufactured from high strength steels due to the high stress performance requirements. Industry has begun to address this challenge with projects such as the Lightweight Forging initiative formed by a range of forging and steelmaking companies [126].

In addition to the reduction of weight and emissions, light weighting offers the advantage of reduced rotational mass and inertia [160] as well as the reduction of noise and component wear [71, 164]. These benefits, combined with a rapidly expanding gear market, at an annualised growth of $5.6 \%$ from \$221 billion in 2019 to \$285 billion in 2024 [52] demonstrates the potential for lightweight gears.

\section{Technologies for manufacturing lightweight gears}

There are a vast number of techniques applied to achieve weight reduction of gears. A review of the most commonly used techniques is presented in the following sections.

\subsection{Machining}

The most commonly used method to reduce the weight of traditional gears is the use of machining to produce thin webs in the low-stress regions of the gear, specifically the material centre [110, 130]. However, there are limitations to potential weight savings due to the overall reduction in stiffness [91] of the gear as a result of the reduction in second moment of area, leading to 'bowing' when axially loaded such as for helical gears [112]. This has the effect of increasing the overall bending and contact stresses experienced by the gear [112]. An example of gear webs at the centre of the gear for the purpose of light weighting is shown in Fig. 1.

\subsection{Casting}

Material substitution is seen as a viable approach to further reduce the weight of components such as gears. Materials traditionally used to produce gears are high strength metallic alloys or polymers [154]. Polymer gears are limited to low power transmission applications or those requiring low cost, noise and corrosion resistance [102]. Metal alloys such as carbon steels are commonly used for higher performance applications, with their manufacturing methods further affecting their load and fatigue capabilities [68]. Due to their vastly differing applications, the literature has explored the potential for polymer-metal gear combinations.

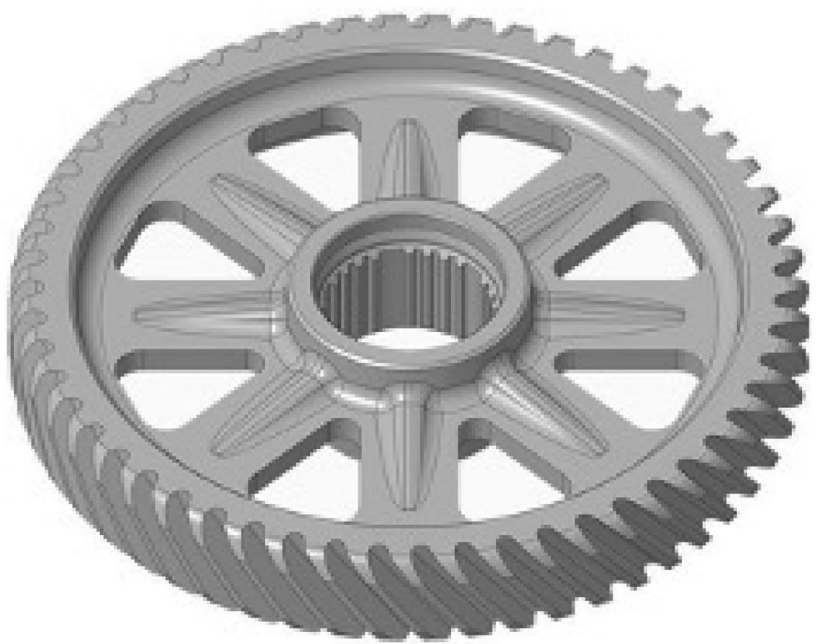

Fig. 1 Lightweight gear with machined webs in low stress interior [67]

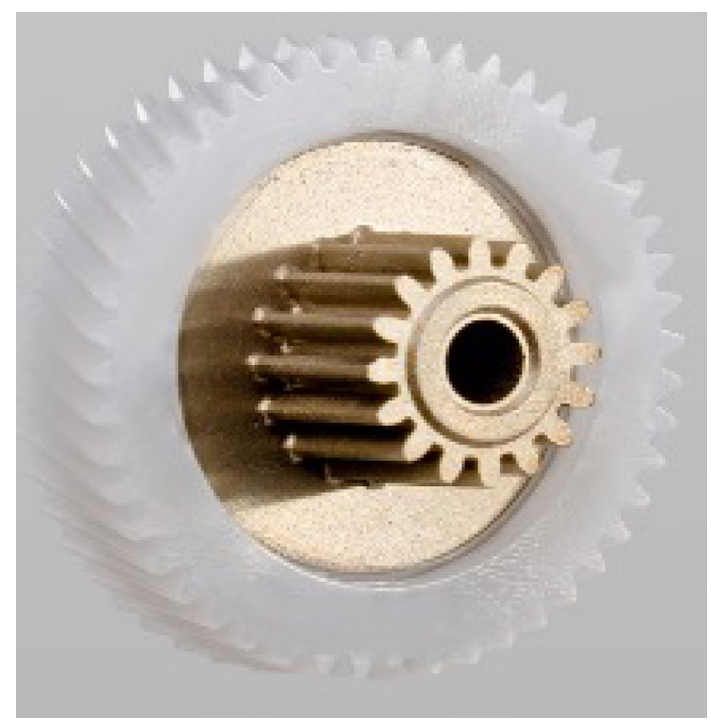

Fig. 2 Polymer overmould on metal gear [156]

This offers the possibility of manufacturing techniques such as over-moulding the lower melting temperature polymer over a metal workpiece as demonstrated by several authors [109, 111, 124, 125]. By extension, composite-metal gears have recently been experimentally investigated $[64,65]$ and numerically modelled [53]. However, the use of completely different material classes provides limitations to their operating conditions, such as temperature, and thus limits the application. An example of a multi-material metal gear with polymer overmould is shown in Fig. 2.

The production of lightweight gears from dissimilar metals such as aluminium and steel has been investigated by Oberle [109] and Grange and Hanink [58], utilising the 
casting of molten aluminium into a mould containing a steel segment. However, the use of over-moulding or casting techniques is limited to two materials of substantially differing melting temperatures.

\subsection{Mechanical assembly}

To avoid manufacturing operations involving metals at different phases, the literature has proposed simpler approaches to manufacturing multi-metal components such as manufacturing each material separately and assembling through means of mechanical fastening or welding (Fig. 3). Wells [166] proposed the production of a composite polymer-steel gear through mechanical connections, with the steel outer profile containing the machined gear teeth. Wadleigh [163] utilised friction welding to form the bond between the two materials. Taniguchi and Shioiri [149] proposed press fitting to assemble the constituent parts although it was found that part distortion required post-form machining operations.

\subsection{Forging}

The process of producing gears with the most favourable mechanical properties is forging. Forged components have resulted in an increased impact strength by $30 \%$ Abdel-Rahman and Dean [1] and double the fatigue life of machined parts Abdel-Rahman and Dean [1]. The production of lightweight forged multi-metal components exist in a wide range of applications, including the production of aluminium and steel control arms [81, 88]. The use of forging for bi-metal gear production dates back to as early as the 1970s [132]. Studies by Politis et al. [118] and Chugreeva et al. [38] have

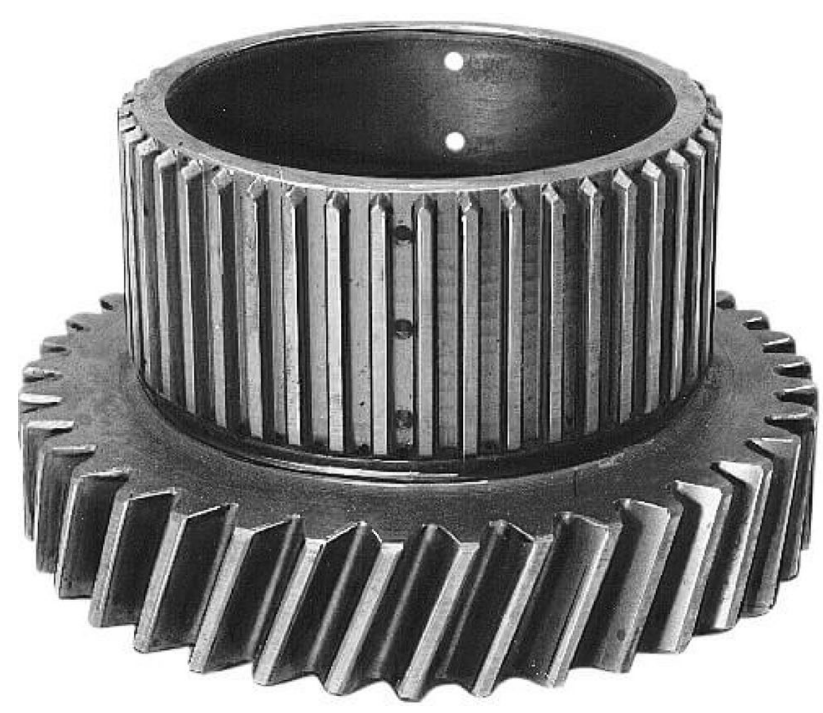

Fig. 3 Welding of a spur and helical gear to produce a composite gear [104] demonstrated the production of bi-metal spur gears and bevel gears respectively through forging, with Chavdar et al. [32] investigating the principle of hydroforging. In addition, Meißner et al. [97] analysed the performance of helical gears manufactured from multi-component forging and layered sheet stapling. The potential mechanical performance as being similar to traditional single material gears has been investigated by Yilmaz et al. [171] and Politis et al. [119]. An example of a forged aluminium-steel bi-metal gear is shown in Fig. 4.

As forging is the process which offers the greatest potential for achieving both lightweight gears with superior mechanical properties, the aim of this paper is to provide a review of the literature associated with bi-metal gear forging and address the key requirements in the production of a successful gear. Section 3 discusses the various means of producing bi-metallic preform workpieces with Sect. 4 discussing the range of heating methods available. Section 5 discusses the key challenges and proposed improvements of a bi-metallic interlayer to prevent separation of the materials during operation. Section 6 discusses the modelling methods being developed to effectively simulate the forging process, intermetallics and optimisation of multi-metal gear forging. The paper concludes with the proposed ideal processing route in the authors' opinion for the production of successful bi-metallic gears and future research directions to address the remaining technical challenges to enable multimetal gears to be applied broadly in an industrial setting.

\section{Bi-metallic forging and preform production}

A review of the literature has demonstrated numerous avenues and processing routes in the forging of multi-metal gears. The majority of the studies involve the use of a traditional forging press, with key differences being in the production of the dissimilar metal blanks and associated heating

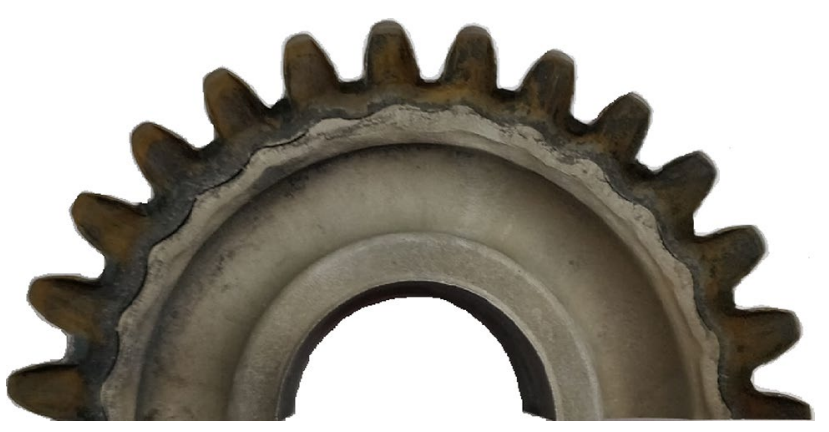

Fig. 4 Forged bi-metal gear from an aluminium centre and exterior steel ring [120] 
methods to overcome the challenge of differing thermal properties of the metals.

\subsection{Bi-metal cast workpiece}

The production of a single cast preform manufactured from dissimilar metals was proposed by Miller [98], which has since been applied industrially [96]. In this process, two dissimilar metals are used, with the outer material being tin bronze and the inner material being yellow brass. Through the use of centrifugal casting, tin bronze was first added to the rotating mould, followed by molten yellow brass which produces a single multi-metal workpiece. According to the authors, the outer material is subsequently machined to produce the final gear teeth form. It should be noted that the process provides the advantage of only requiring material handling for a single workpiece thus significantly reducing handling operations on the factory floor. The centrifugal bimetal blank casting process could be further adapted to gear forging by replacing the final gear tooth machining operation with a forging process. However to date there have been limited studies in combining these two processes. Moreover, the bi-metal casting process focused on the use of brass and bronze, which are materials of similar melting temperature and therefore the production of alternative preforms such as aluminium-steel pairs may result in additional challenges such as the solidification of the outer steel prior to aluminium, leading to inconsistencies in the interlayer surface which is discussed further in Sect. 5.

\subsection{Co-Extrusion of dissimilar metals}

The co-extrusion of an inner bar and outer sleeve material has been studied in several research works as an alternative method to the production of multi-metal preforms. The process has been investigated at both cold or elevated temperatures, with elevated temperatures enabling the two materials to be welded at the interface. By machining to appropriate

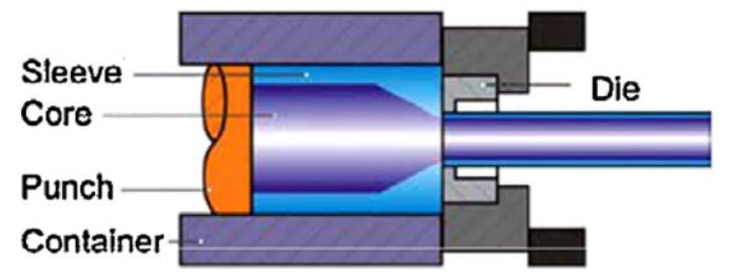

(a) length, the preforms can subsequently be used in a forging operation. Such an approach was proposed by Tekkaya [150] as shown in Fig. 5 a.

The co-extrusion of dissimilar metals introduces processing parameters including relative material flow and friction that may induce tensile and shear stresses resulting in surface cracking and failure [49]. Groche et al. [60] performed a microscopic analysis of the weld interface between steel and aluminium material pairs formed with this process revealing only a small diffusion zone and significant oxide build-up at the weld inter-face. It is suggested in the study that a promising material pair for lightweight high strength preforms is the co-extrusion of aluminium and titanium as this exhibits no intermetallic phases or oxygen-contamination resulting in a robust bond. Micro-structural effects of a dissimilar pair interface are discussed in detail in Sect. 5.

Cold forged bonds on composite shafts were experimentally and analytically investigated by Ossenkemper et al. [113]. In this work, the authors utilised the backward extrusion of a steel sleeve material into which an aluminium core was inserted. The authors' investigated the strength of the bond via push out tests and determined that the lack of metallurgical bonding resulted in a relatively weak joint, which could be improved through the addition of micro fitting via the use of a sand blasted surface.

Thurer et al. [153] investigated the co-extrusion of aluminium alloy EN AW-6082 with case-hardened steel 20MnCr5. Utilising the Lateral Angular Co-extrusion (LACE) process, a central steel rod was extruded with aluminium EN AW-6082 at an angle of $90^{\circ}$ between the punch direction with the profile's exit port being co-extruded (Fig. 5b). Through this method intermetallic phases such as $\mathrm{Al}_{3} \mathrm{Fe}$ of 2-7 $\mu \mathrm{m}$ were formed on the joining zone between aluminium and steel, with a temperature of $540{ }^{\circ} \mathrm{C}$ being sufficient to promote adhesion between the two metals. Moreover, through a modified billet geometry and the inherent nature of material flow, it was possible to remove surface oxides thus forming an adequate bond. However, with the

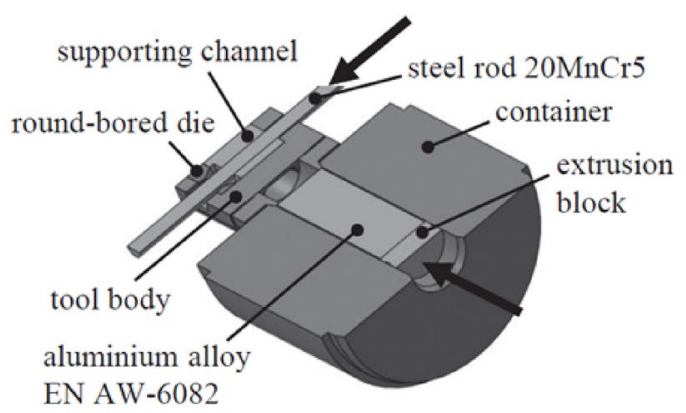

(b)

Fig. 5 Extruded pre-forms: a Direct co-extrusion of a bi-metal preform [150], b LACE co-extruded preforms [153] 
proposed method high strength material is placed in the centre rather than on the exterior, which may be of limited use for bi-metal gear preforms. Should the material pairs be reversed the method may be feasible for gear preforms.

\subsection{Shrink fitting}

An alternative method to combine two dissimilar metals prior to forging is the shrink fitting technique, which is commonly used for bi-metal assembly and component production [40]. The process is still widely used today, to optimise performance or achieve lightweight structures, such as lightweight bi-metallic bearing bushings consisting of $20 \mathrm{MnCr} 5$ steel on the internal diameter and AA6082 aluminium on the external diameter Behrens et al. [17].

Lätzer et al. [84] and Qiao et al. [122] developed knurled interference fits consisting of a shape profile that improved the performance compared to conventional interference fits. Liewald et al. [92] utilised lateral extrusion of a shaft to a hardened, thin-walled hub to manufacture a combined complex shaft-flange component. Through the use of a modular tool and radial preloading, the authors were able to avoid critical tangential tensile stresses during joining. This combined with the use of a polygon profile in the hub, produced a component with twice the torsional strength compared to conventional thermal shrinkage. Matsumoto et al. [95] utilised the indentation of a cold shaft into a hot disc, where the thermal shrinkage established a bond where $20 \%$ of the overall bond strength was due to mechanical clamping and $80 \%$ due to metallurgical bonding.

Whilst these studies did not focus specifically on producing preforms for bi-metallic gears, the methods employed could be transformed into lightweight gear applications.

\subsection{Welding}

Several research works have proposed variants of welding to join dissimilar metals prior to forging. Welding of dissimilar metals may be achieved by metal inert gas welding, submerged arc deposition, plasma-transferred arc

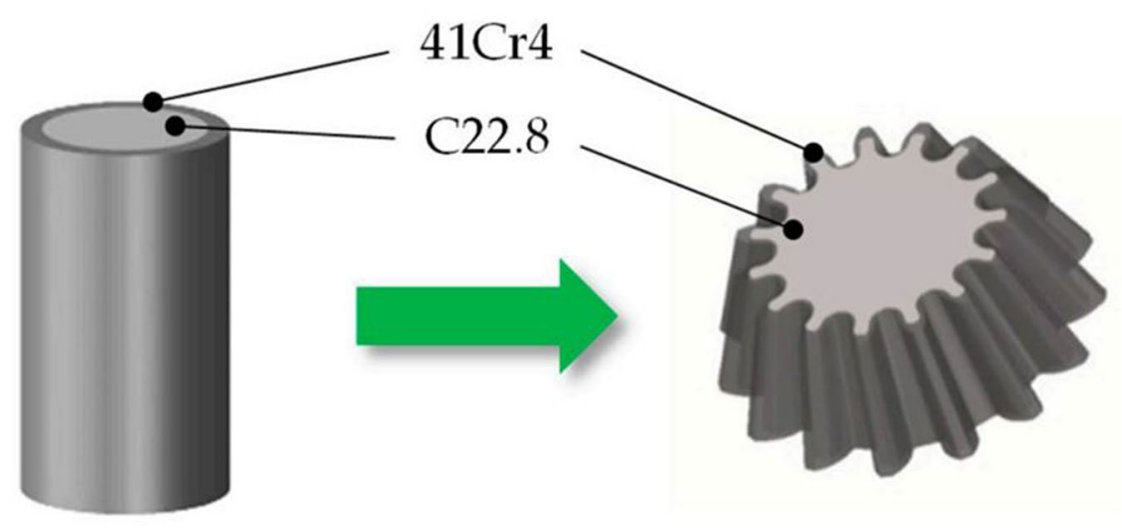

(a)

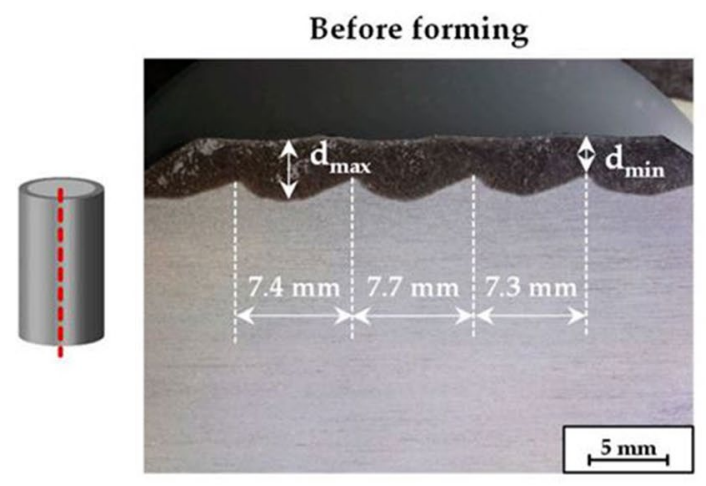

(c) (b)

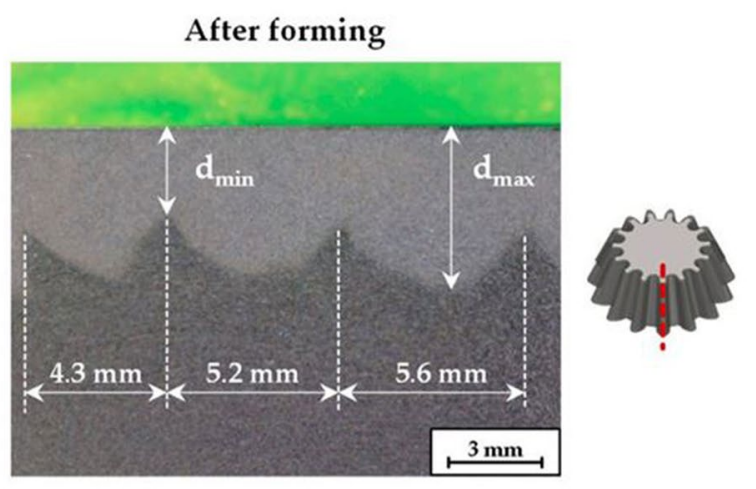

(d)

Fig. 6 a Deposition welded preform, b Forged bi-metal gear [51], $\mathbf{c}$ Micrograph of the bond zone before forming, $\mathbf{d}$ Micrograph of the bond zone after forming [38] 
(PTA), laser deposition welding and electro-slag-welding [6]. Chugreeva et al. [38] utilised deposition welding to produce a preform for a forged bevel gear manufactured from a cylindrical base material coated with a dissimilar metallic layer. This is demonstrated in Fig. 6a and b. The authors' state that although the workpiece is advantageous in that it is securely joined prior to forming, deposition welding has the disadvantage of the produced heat affected zone, which may negatively affect the microstructure of the preform, including increased brittleness and hardness. However, subsequent forging can counteract these phenomena to produce a gear free from pores and a coarse microstructure. An evaluation of the metal interface found that post-forging, the bond zone demonstrated a contour with a jagged edge which was sustained even post-forging into the gear shape. Therefore, welded preforms require careful analysis to ensure stress concentration sites do not affect material performance and the minimal steel thickness is sufficient for the application.

Behrens et al. [16] also investigated welding for the production of straight bevel gears made from martensitic steel
(X45CrSi9-3) on the tooth surface and carbon steel (C22.8) in the core. The preform materials were joined by laser hotwire cladding, machined and subsequently hot forged to the final geometry. The authors found that the bonding zone was defect free, including being free of cracks, separation and porosity and also demonstrated a complete metallurgical bond after the combination of welding and forming. However, as expected the variations in strain during forging resulted in a non-uniform distribution of material at the tooth tip and root.

An alternative to traditional welding methods is electromagnetic pulse welding, which is a process that involves high speed impact, with velocities up to several hundred $\mathrm{m} / \mathrm{s}$ and pressures up to several thousand MPa, with subsequent plastic deformation of the workpieces [93]. The method can possibly be used to produce a single bi-metal blank through the assembly of dissimilar inner cylindrical material and an outer sleeve. With the electromagnetic pulse welding process, the two metals are joined by the impact and breakup of surface contaminants and oxide layers thus promoting welding. The method is shown in Fig. 7a where the application

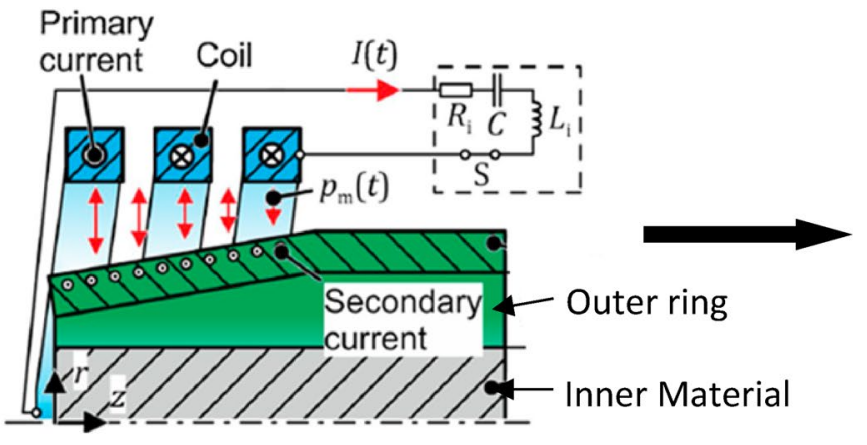

(i)

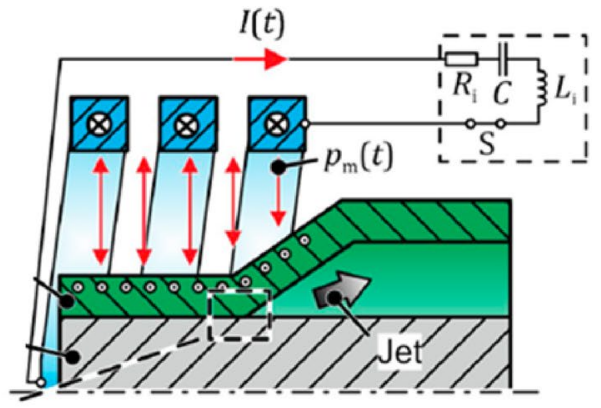

(ii)

(a)

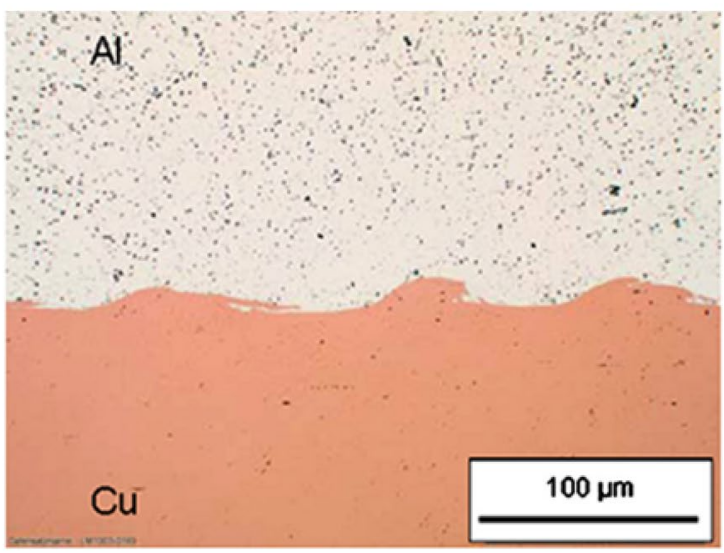

(b)

Fig. 7 Electromagnetic pulse welded: a Acceleration and collision of outer sleeve to core (1) Before and (2) After the process [93], and b Aluminium-copper blank interface [55] 
of a current in the coil creates a magnetic field that forces the outer sleeve towards the inner sleeve materials, and through the process of 'jetting' forces air and oxide layers away from the material interface resulting in close metalto-metal contact. According to Groche et al. [60], there is limited knowledge on the optimal parameters to form solid state bonds with this method and therefore preforms can only be produced through trial and error methods. However, the literature generally agrees that the variables of collision angle and speed of impact are of significant influence to the success of a multi-metal bond [115]. It should be noted that bonds produced between two metals with this process result in a wavy edge due to the shock waves travelling through the workpieces, as shown in Fig. 7b [55]. Therefore it is possible that bi-metal preforms could be produced as a single workpiece before subsequent forging operations.

The welding of a bi-metal preform through friction welding has been demonstrated through the rotation of the inner workpiece relative to the exterior material. Through the relative motion, frictional work results in the shear stress of the material being exceeded locally, resulting in the combined plastic work and elevated temperatures forming a bond between the two materials. Friction stir welding is commonly found in the joining of dissimilar sheet metals including aluminium-aluminium pairs [103] and aluminium-steel pairs [90]. However, the main limitation of this method on bulk components is the requirement of a friction stir welding tool that applies local deformation and heat at a limited depth. Inertia friction welding joints can be formed through the direct contact of the cross-sectional areas of two cylindrical materials. The rotation of one of the materials forms a weld across the contact surface area. Effective joints were successfully formed on materials including high strength nickel superalloys [43]. The friction welding of a solid central material and an outer ring presents the challenge of an air gap between the two materials in order to assemble the workpiece. It may be possible to utilise rotational friction welding in combination with an interference fit ensuring the outer circumference of the central material is in direct contact with the inner radius of the exterior ring, although the effectiveness of this method presents numerous challenges thus requiring further investigation.

Domblesky et al. [44] produced bi-metal preforms from copper, aluminium and steel pairs to determine weld characteristics such as grain structure at the interface. Behrens et al. [15] investigated the performed metallographic analyses and evaluated the bond strengths for laser beam welding and friction welding of a bi-metallic C22.8 (1.0460) and $41 \mathrm{Cr} 4$ (1.7035) steel rod. The results do demonstrate high strength bond formation, with the component failing in the lower strength base material steel (1.0460) rather than the bond region for both forms of bonding. However, the studies focused on the joining between the cross-sectional areas rather than along the length of the two components, and could be repeated by a joint formed between a central and sleeve material.

\subsection{Un-bonded preform materials}

There have been several research works that have pursued the avenue of forging multi-metal components through the forging of assembled workpieces as opposed to first joining and then forming the components. Wu et al. [169] and Politis et al. $[117,118]$ investigated the forging under hot and cold conditions respectively of spur gears through the telescopic assembly of an outer high strength ring and an inner cylindrical core material. The studies showed that the inherent flow behaviour of the two materials enabled the secure locking under rotational and axial directions with the interface conditions being favourable for potential diffusion bonding. Figures $8 \mathrm{a}$ and $\mathrm{b}$ show a bi-metal gear produced from an aluminium AA7075 central material and EN 817M40 steel outer material. It was noted that as the materials were unbonded prior to forging, there is the risk that regions of the completed gear may have an unbonded interface. However, optimisation of the forging process may prevent this and the simplicity of eliminating an additional bonding stage may make this production method convenient.

\section{Blank heating methods}

Bi-metal components are commonly cold forged in order to avoid the complexity of controlling thermal parameters of dissimilar metals. However, for materials of low ductility, heating is required and involves the consideration of different melting temperatures, thermal expansion coefficients, heat transfer and microstructural changes. Due to the differing thermal properties such as expansion coefficient, steelaluminium material pairs require the steel to be heated to a minimum temperature of $900{ }^{\circ} \mathrm{C}$ whereas aluminium must be at least $400{ }^{\circ} \mathrm{C}$ but not exceeding $500{ }^{\circ} \mathrm{C}$ to avoid melting [19]. Careful selection of temperatures can ensure that despite significantly differing expansion coefficients, with aluminium twice that of steel, the materials can expand and contract at a similar level thus avoiding excessive separation or substantial compressive stresses. The recommended thermal processing windows for aluminium-steel pairs are presented in Fig. 9.

According to Fig. 9, a steel ring profile heated to $1000{ }^{\circ} \mathrm{C}$ requires the temperature of the aluminium core to not exceed $435{ }^{\circ} \mathrm{C}$, otherwise the aluminium will contract more than the steel resulting in a gap being formed after cooling. Conversely, if the temperature of the aluminium is lower than $435{ }^{\circ} \mathrm{C}$, thermal contraction of the steel will be greater than 


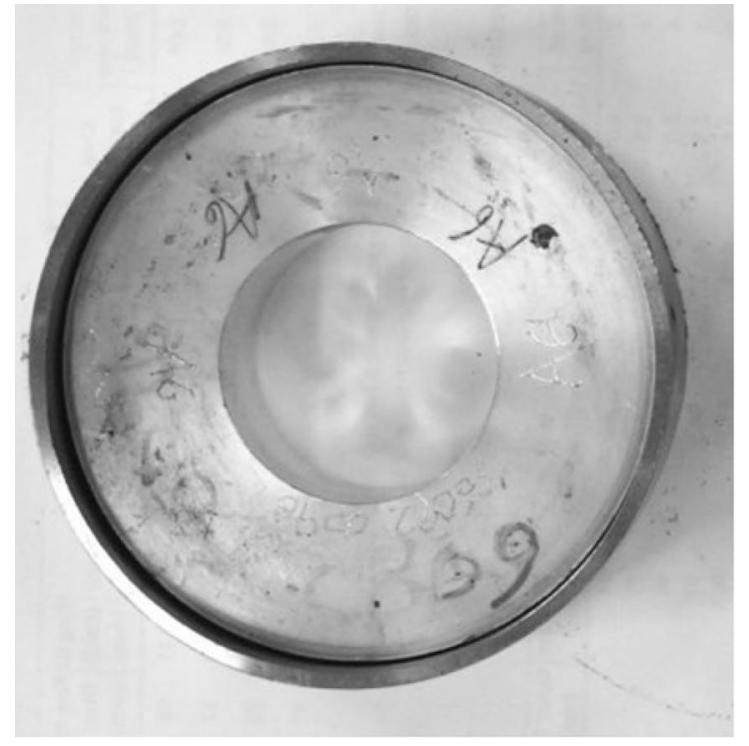

(a)

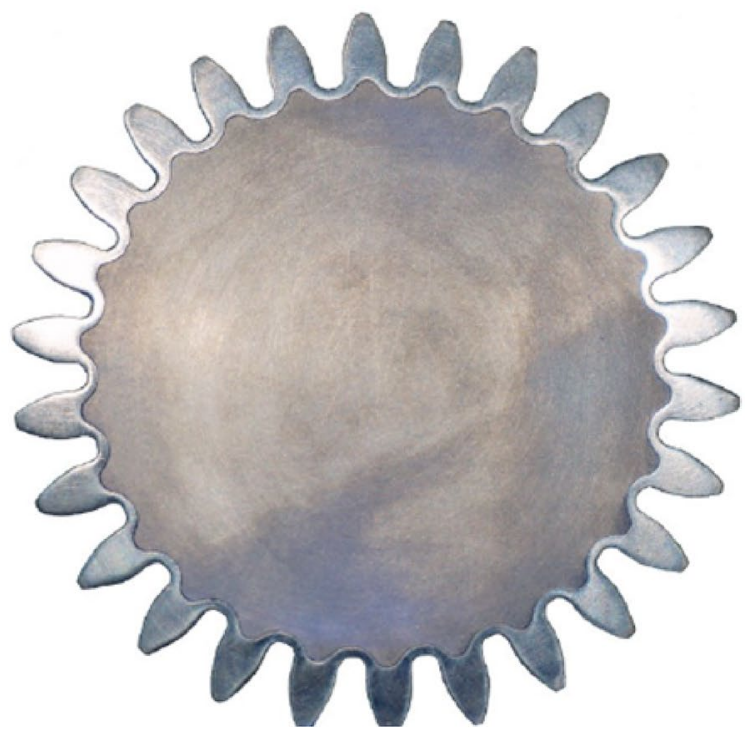

(b)

Fig. 8 Bi-metal gear: a Individual steel ring and aluminium core material, b Forged bi-metal gear [120]

Fig. 9 Temperature processing window for aluminium and steel to avoid separation of materials [19]

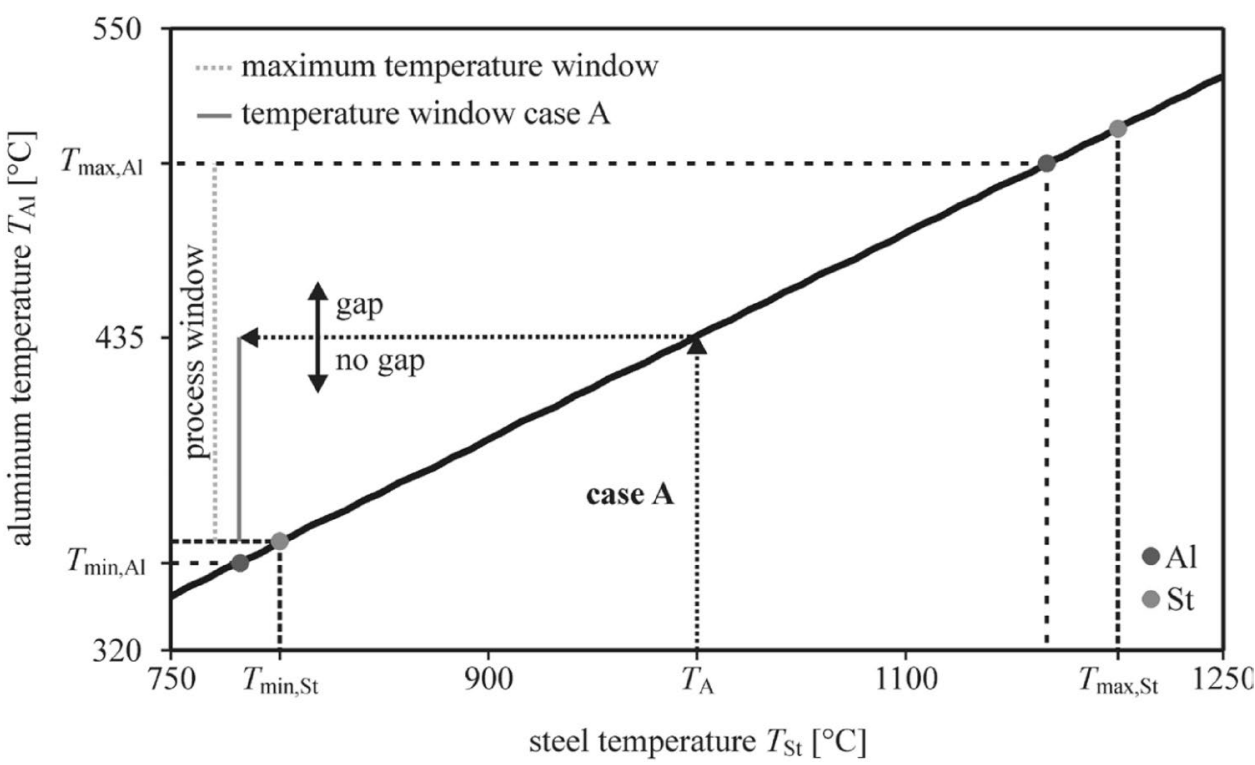

the aluminium which could result in excessive hoop stresses and possible fracture of the ring.

In order to achieve the required temperature profiles, two methods to heat the metal preforms were mainly explored in the literature: chamber furnace and induction heating.

To this end, Politis [120] investigated the forging of workpieces, heated separately in individual chamfer furnaces and subsequently telescopically assembled in the die and forged in a single operation. Two chamber furnaces were utilised in the study with the aluminium core being heated to $400{ }^{\circ} \mathrm{C}$ and the steel ring to $950{ }^{\circ} \mathrm{C}$. It was suggested that for a greater production run two conveyor furnaces could be used, each set to the target temperature for the selected alloys. The method was found to be effective for heating the workpieces in a laboratory setting although the heating time was in the order of minutes which would limit production efficiency. Moreover, in the study the workpieces were transported from the furnaces to the tool resulting in limited control of the temperature due to air cooling. It should be noted that disparities in heat transfer coefficient and thermal contraction may result in separation of the two materials leading to the presence of a gap at the interface as shown in the bi-metal gear forging study by Politis [120] and presented in Fig. 10. 


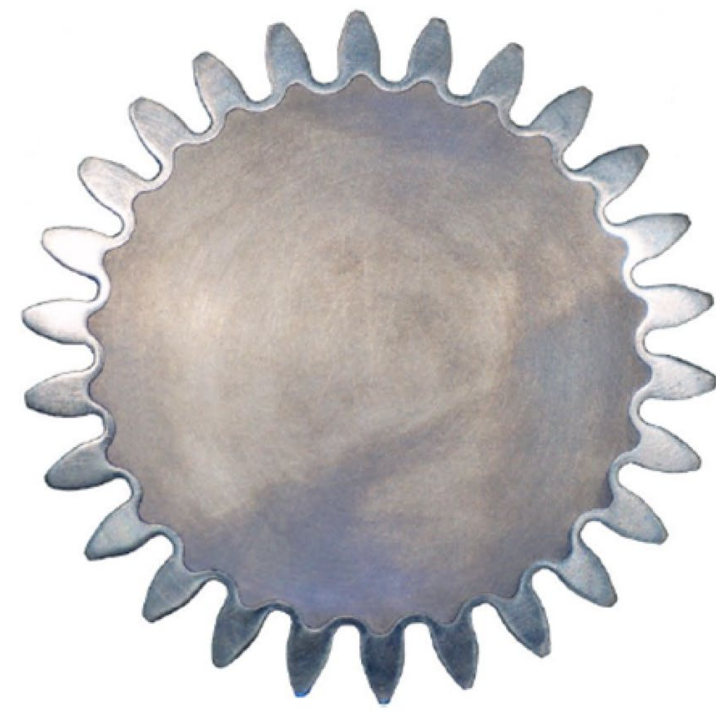

(a) Cross section of gear

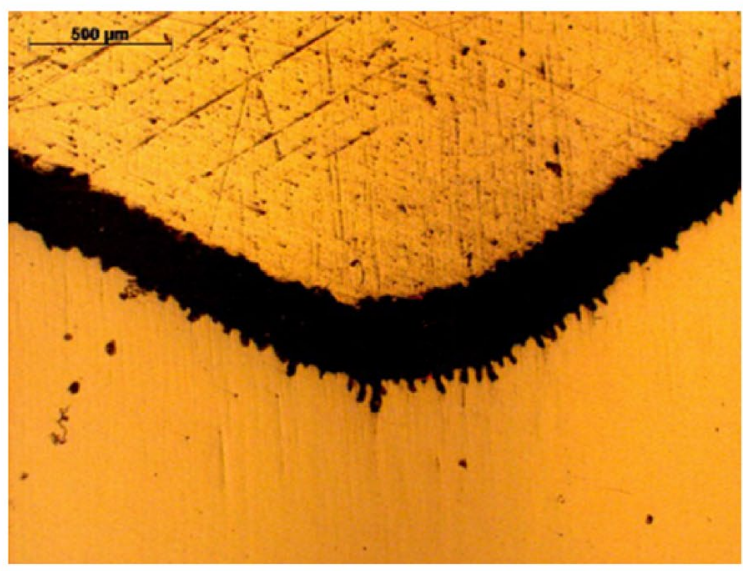

(b) Microscopy of interface

Fig. 10 Separation between the materials following the bi-metal gear forging [120]

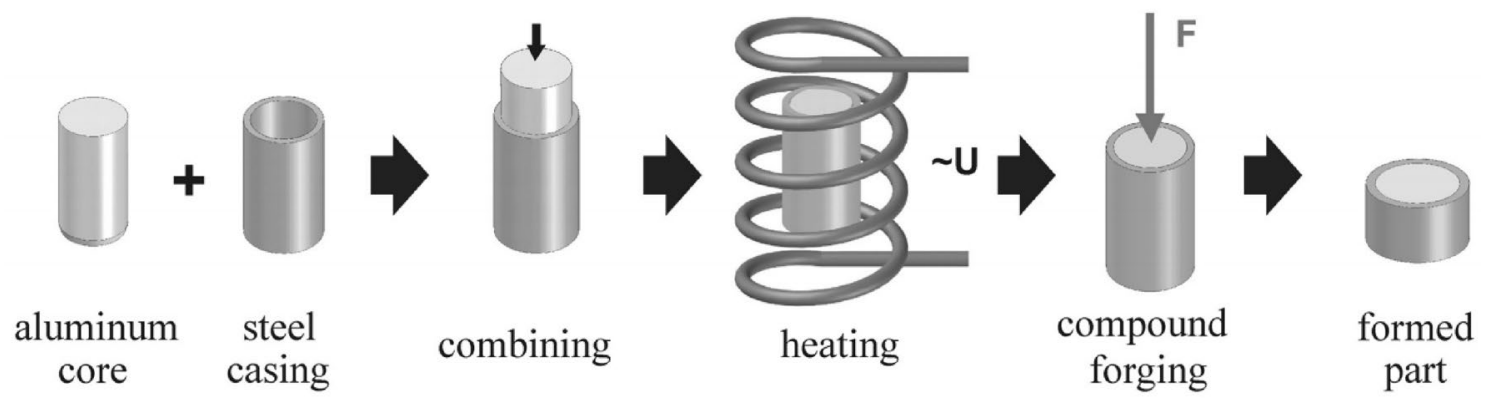

Fig. 11 Induction heating method for combined aluminium steel preform [19]

The use of induction heating for aluminium-steel pairs for bi-metal forged bushings was investigated by Behrens et al. (17). Behrens and Kosch (19) developed a heating strategy to utilise induction heating for aluminium-steel combinations. In this work, the authors first combined an aluminium core with a steel ring and heated the preform simultaneously as shown in Fig. 11. It is stated that the presence of the air gap between the two metals is significantly influential on the heating parameters and can be beneficial as the air gap results in the heating of aluminium only by radiation rather than conduction, thus enabling heating control.

The use of induction heating enables additional control compared to furnace heating although with added complexity requiring the calibration of electromagnetic parameters such as electrical conductivity, permittivity and permeability in addition to thermal conductivity and heat transfer coefficient. Moreover, coil design and frequency is essential to ensure adequate heating. Therefore, the common approach taken by industry to optimise these parameters is trial and error. It should be noted that induction heating is significantly faster in achieving the target temperature than chamber furnace heating, with an aluminium sample temperature of $500{ }^{\circ} \mathrm{C}$ being achieved within $20 \mathrm{~s}[17,18]$ compared to several minutes for a chamber furnace.

Induction heating experiments on steel-aluminium and steel-copper pairs determined that it is the outer layer (steel) that determines the heating effect as opposed to the core material, with the copper and aluminium materials not responding to induction heating as significantly as the steel [131]. This is demonstrated in Fig. 12a.

In the work performed by Goldstein et al. [56] it was found that electromagnetic end effects could lead to overheating of parts of the workpiece resulting in localised melting. Therefore, it is possible that post-form operations, such as machining of the workpiece ends may be required to remove regions of unfavourable interface joint 


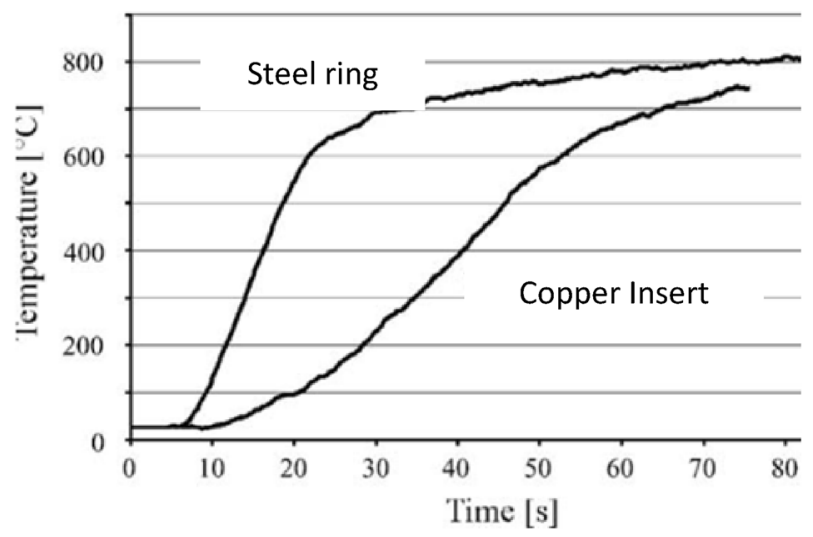

(a)

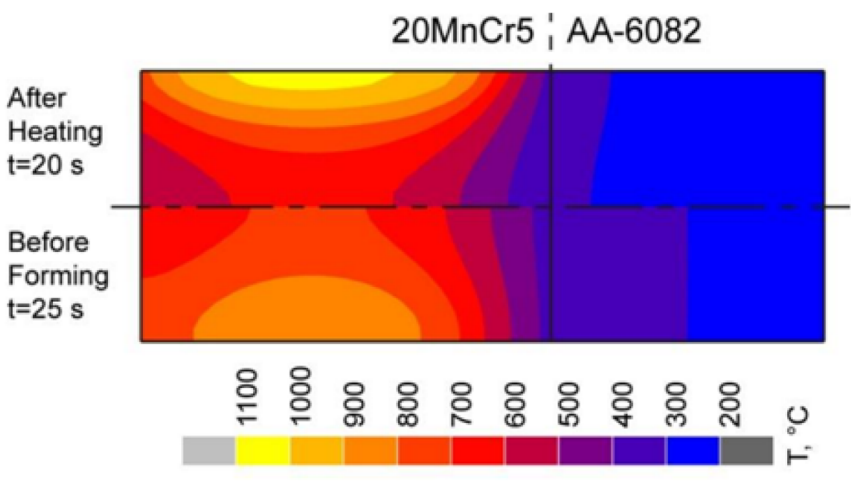

(b)

Fig. 12 a Temperature-time graph of induction heated bi-metallic preform with steel exterior and copper interior [131], b Temperature uniformity of adjacently bonded steel and aluminium alloys [56]

conditions. Moreover, the authors' found that aluminium, with its greater heat transfer coefficient, is more likely to exhibit uniform temperature after heating compared to steel. In the study, the authors' found that the temperature within the steel workpiece was not uniform even after $20 \mathrm{~s}$ of heating. It should be noted that temperature distribution studies were formed on workpieces with dimensions of $40 \mathrm{~mm}$ solid diameter, and therefore steel in the form of a thin exterior ring will exhibit a greater likelihood of temperature uniformity in a shorter time period.

\section{Joining between multiple materials}

\subsection{Types of bonds}

One of the greatest challenges to the structural integrity of a multi-metal component is the joint between the dissimilar materials. In the case of bi-metal gears, a bond between the two dissimilar metals would form either as part of the pre-form manufacturing process as discussed in Sect. 3 or after forging of the gear. According to the literature, joints between two formed materials can be grouped into 3 categories: (1) form-closed joints; (2) force-closed joints; or (3) metallurgical joints as shown in Fig. 13 [59].

Form-closed joints (Type I) involve mechanical locking, where the relative material flow between two components is prevented. This occurs when a residual stress or other force causes friction between the materials, resisting relative motion. Type II force-closed joints require compression of the materials resulting in friction preventing the relative movement of the materials [101]. Finally, a metallurgical joint (3) consists of a cold welded or diffusion bonded interface joint, where the parts are bonded at an atomic level.

Mechanical joining by plastic deformation between dissimilar materials has been well established in industry. In the case of sheet materials, this is commonly achieved through clinching, hemming [105] and self-piercing rivets [100]. For bulk forming such as forging operations, mechanical joining has been demonstrated on both a macro and micro scale. Politis et al. [117,118] stated that macro-mechanical and micro-mechanical joining occurred between two materials
Fig. 13 Physical joints created through forming [59]

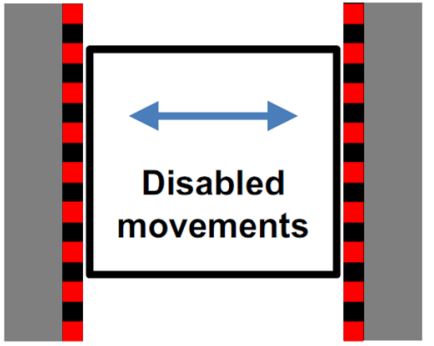

(a) Form-closed

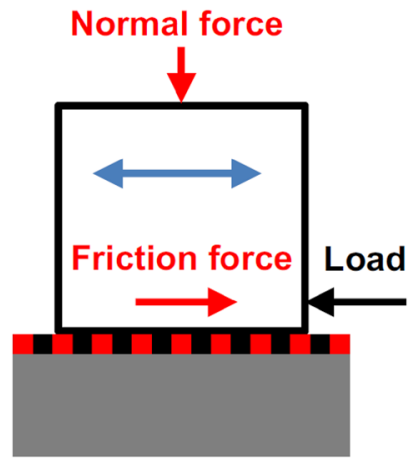

(b) Force-closed

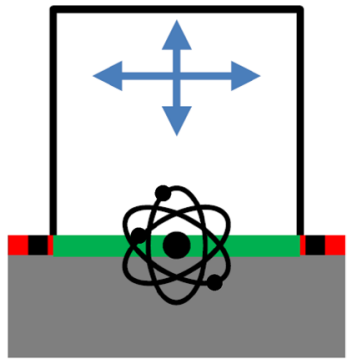

(c) Metallurgical 


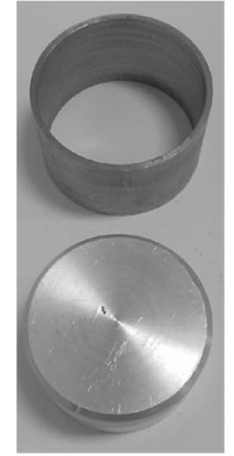

(a)

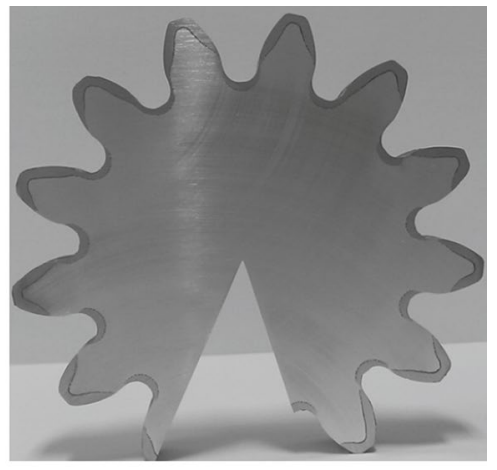

(b)

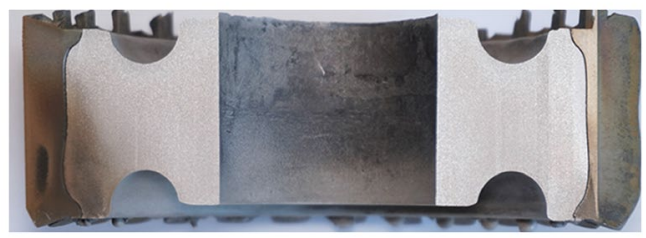

(c)

Fig. 14 Mechanical joint achieved by plastic deformation of aluminium and steel components: a Steel ring and aluminium core preforms, b Forged gear shape-horizontal cross section [117], c Vertical cross section [120]

forged into a bi-metal gear as shown in Fig. 14. In the study, forging of an aluminium central cylinder material and a steel exterior ring were conducted, with the inherent material flow into the gear tooth profile completing the joint whilst resulting in a $50 \%$ weight reduction of the component. Similar investigations on bi-metal workpieces comprising of a steel outer ring and brass or copper inner cylinder were performed by Misirli et al. [99].

Mechanical joining by forging has also been achieved for the manufacture of a control arm by Kroner [81] and Leiber [88]. In these studies the authors optimised the strength to weight ratio by utilising an aluminium flange and steel insert thus achieving a $47 \%$ weight saving compared to conventional steel components. Moreover, Kitamura et al. [79] developed a method of joining a flange to a shaft by cold forming which improved the transmission of torque.

Whilst mechanical joining can be achieved with relative ease through appropriate design and processing parameters, the greatest challenge is the formation of the Type III metallurgical or diffusion bond. This is discussed further in Sect. 5.2.

\subsection{Effect of metal surfaces on metallurgical bonding}

Metallurgical joining during hot forging is commonly known as 'forge welding'. Forging between dissimilar metals is not a recent phenomenon, having been used for thousands of years [9]. In fact, forge welding is the oldest known welding method for iron and steel, having been used in the production of pattern welded blades in the process known as "Damascus Steel" [161]. During these early applications, forge welding consisted of: (1) roughening and cleaning the mating surfaces; (2) heating the mating region to $50-90 \%$ of material melting point [45]; (3) applying a powder flux (such as borax and iron filings) to remove oxide layers [31]; and (4) overlapping the mating surfaces and forming through repeated hammer blows [121].

Repetition of the above cleaning and forming procedure for a successful bond is primarily the result of obstacles to metallurgical joining in multi-metal forming such as the presence of contaminants or passivation layers [22, 25] as shown in Fig. 15. As can be seen from the figure, even highly polished and cleaned metallic surfaces contain grease, water vapour and oxide contaminants on a nano-metre scale [75]. The presence of contaminants on two metal surfaces presents a barrier to the formation of high quality metallurgical bonds $[4,75]$. In particular, chemically stable oxide layers,

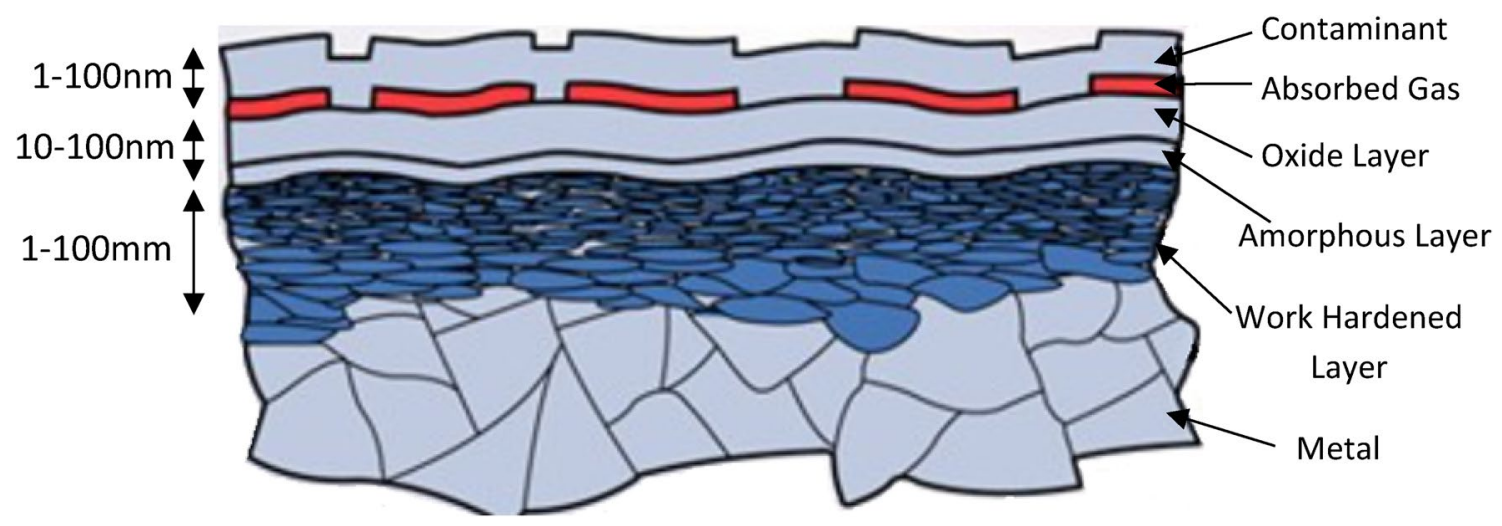

Fig. 15 Contamination layers on a metal surface [73] 
such as those on aluminium alloys make diffusion bonding extremely difficult [4].

The majority of contamination layers such as grease, water and oil vapour can be substantially removed by degreasing, with petrol or solvents, although this may leave behind a layer between 1-5 $\mu \mathrm{m}$ and 10-100 molecules thick respectively [75]. The oxide layer however is significantly more challenging to be removed as metal surfaces are quickly saturated by an oxidation layer even after removal [123]. The speed and depth of the oxide layer is dependent on time and temperature. At room temperature, aluminium alloys may experience an oxide film thickness of $1.2 \mathrm{~nm}$ within $15 \mathrm{~s}$ whereas iron can experience $2 \mathrm{~nm}$ within $40 \mathrm{~s}$ [75] with this significantly increasing in thickness and rate of formation at elevated temperatures. According to Kazakov [75], machined iron based parts have transparent oxide films $<0.03 \mu \mathrm{m}$ thick growing to $0.04-0.5 \mu \mathrm{m}$ during tempering temperatures.

The success of bonding is highly dependent on the elimination of these contaminant or passivation layers [25]. With the absence of such layers during direct material contact, interaction forces arise between the interfacial atoms. This is the result of cohesion forces at the surface of the materials affecting chemical binding at the interface. However, according to Rabinowicz [123], the presence of a normal atmosphere demonstrates that free cohesive binding will be saturated by oxidation.

It is well known that carbon steels and iron based materials oxidise readily as the porosity of iron oxide means any present oxide layers provide no protection to the underlying iron. Therefore unlike alloys such as aluminium and copper, steels exhibit severe oxidation well after the formation of an initial layer of iron oxide [21, 116]. One of the earliest oxidation kinetics models are the Pilling-Bedworth-type equation [14] which model the weight gain of the material as a function of oxidation time utilising the parabolic law as shown in Eq. 1:

$\frac{d W}{d t}=k_{p}^{\prime} W$

where $\mathrm{W}$ is the weight gain per unit area caused by oxidation, and $k_{p}=2 k_{p}^{\prime}$ is the parabolic weight constant. The parabolic weight constant is highly temperature dependent, and the results from a number of studies are shown in Fig. 16a [35]. It should be noted that the heating method employed significantly affects the oxide layer formation. Steel heated in an air furnace would exhibit continuously forming thick iron oxide layer, presenting significant challenges to any possible metallurgical bond as shown in Fig. 16b.

\subsection{Intermetallic layers in multi-metal forging}

Metallurgical bonding is described in the literature as a combination of adhesion and diffusion theories [62]. Adhesion is described in terms of the cumulative effects of thermal, electric, chemical and physical interactions on a materials surface. Whilst the quality of a surface bond is characterised in terms of base material properties, movement, stress state and temperature [173], the bond strength between dissimilar metals is heavily influenced by the brittle intermetallic compounds formed at the interface. In the bonding between steel and aluminium alloys, the formation of $\mathrm{Al}_{5} \mathrm{Fe}_{2}$ and $\mathrm{Al}_{2} \mathrm{Fe}$ intermetallics occurs, which may be detrimental to the strength of the bond [41, 48, 54, 114]. It has been stated by Awiszus et al. [5] that brittle intermetallic phases may lead to bond strengths that are $30 \%$ less than the strength of the weaker material pair. An example of the intermetallic layer between an aluminium and steel workpiece is shown in Fig. 17.

Bhushan [22] demonstrated that clean surfaces in close contact, of the order of several nanometres, form a strong adhesive bond. This is the result of van der Waals forces attracting the welding pairs until equilibrium of electrons is achieved. Due to the chemical properties, he showed that adhesion of relatively soft metals such as copper or gold, is generally stronger than the ones for harder metals, e.g. steel. Further discussions regarding the nanoscale formation of bonds can be found in Groche et al. [60].

Regarding the crystal structure of metals, Rabinowicz [123] and Bhushan [22] demonstrated that cubic structured metals, such as iron or aluminium, exhibited high adhesion, compared to the poor self-adhesion for hexagonal metals. Moreover, microstructural parameters, such as the number of grains and orientation of crystallographic planes, is highly influential on adhesion properties. Specifically, crystallographic planes in contact exhibit a higher tendency for self-adhesion than diverse planes. Krupp [82] and Keller [76] found that the lowest adhesion forces were achieved for close packed planes with high atomic density and low free surface energy. Regarding the solubility of dissimilar metals, material tends to be transferred from the softer metal to the harder one.

The effect of adhesion for a range of microstructural orientations and materials against hardness is demonstrated in Fig. 18.

A significant limitation in the direct bonding of dissimilar metals is galvanic corrosion. This is defined as the accelerated corrosion of a metal as a result of being in contact with another metal of higher potential [63], and commonly occurs in mechanical joining such as rivets or welds. Traditionally associated with dissimilar alloys, galvanic corrosion is also observed in similar alloys with a varied chemical composition. Won et al. [167] investigated 
Fig. 16 Modelling oxidation with temperature: a Temperature dependence of $k_{\mathrm{p}}$ for iron oxidation in air [35] and $\mathbf{b}$ Iron oxide formation on steel surface after heating in air [36]

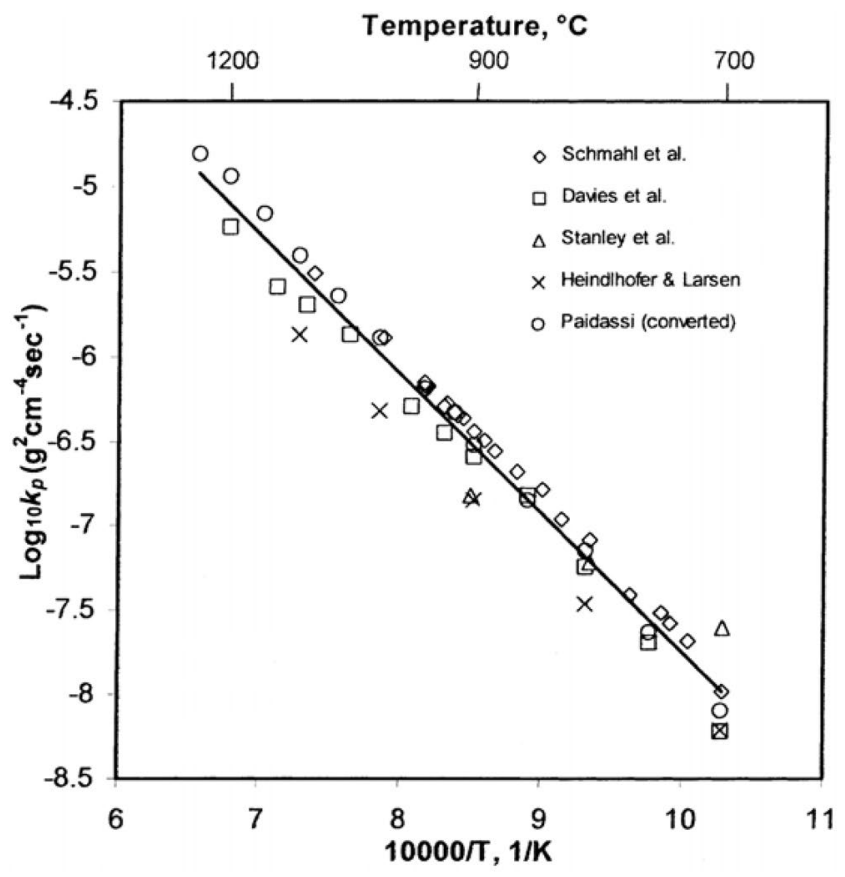

(a)

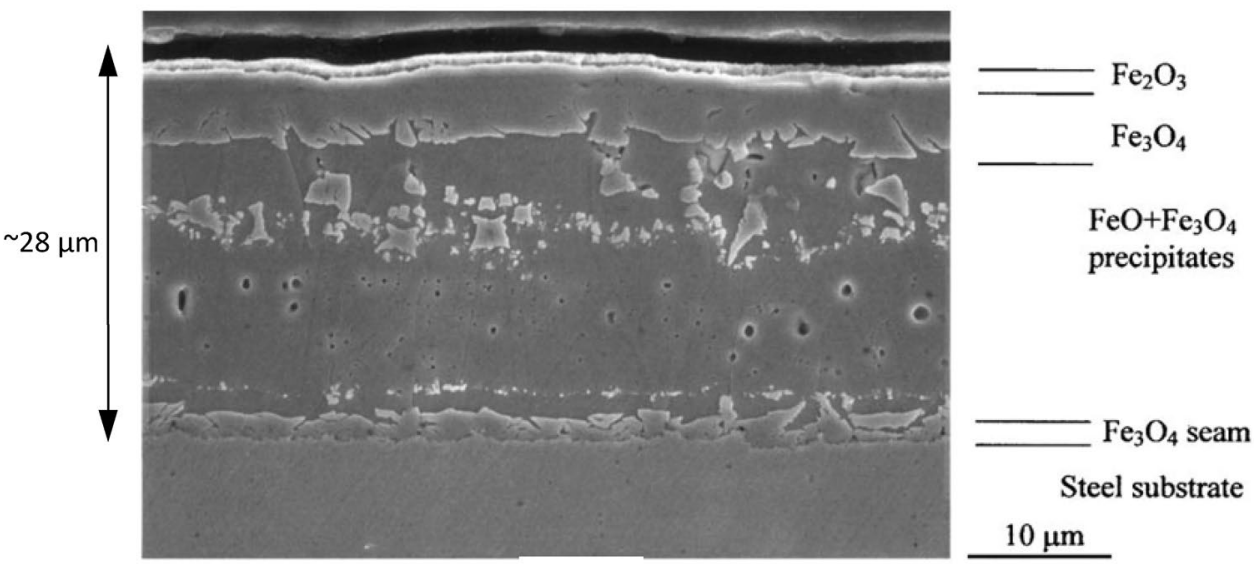

(b)

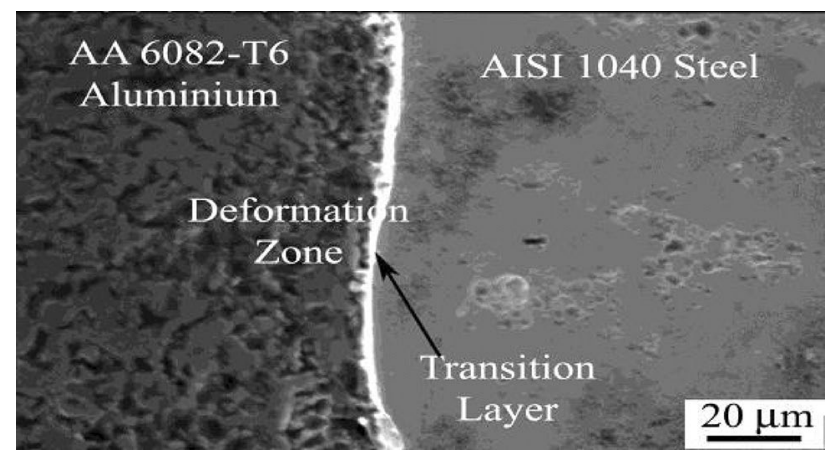

Fig. 17 Intermetallic layer between aluminium and steel part [33] the corrosion between friction welded dissimilar aluminium alloys AA2017 and AA6063. The authors observed severe corrosion at the interface despite both materials being classified as aluminium. This is because the AA2017 alloy has the lowest corrosion potential and acted as an anode when in contact with the AA6063, which has a higher corrosion potential and thus acts as the cathode. More exotic material pairings such as magnesium alloy with aluminium, steel or zinc exhibited much more aggressive corrosion effects [140]. Examples of galvanic corrosion potential for a range of alloys in seawater, considered as a severe operating environment is shown in Fig. 19.

Shi et al. [133] extended the work of bi-metallic corrosion to tri-metal pairs, specifically for the combinations of aluminium 2024, Q235 mild steel and 304 stainless 
Fig. 18 Effect of material and crystal structure on adhesion [142]

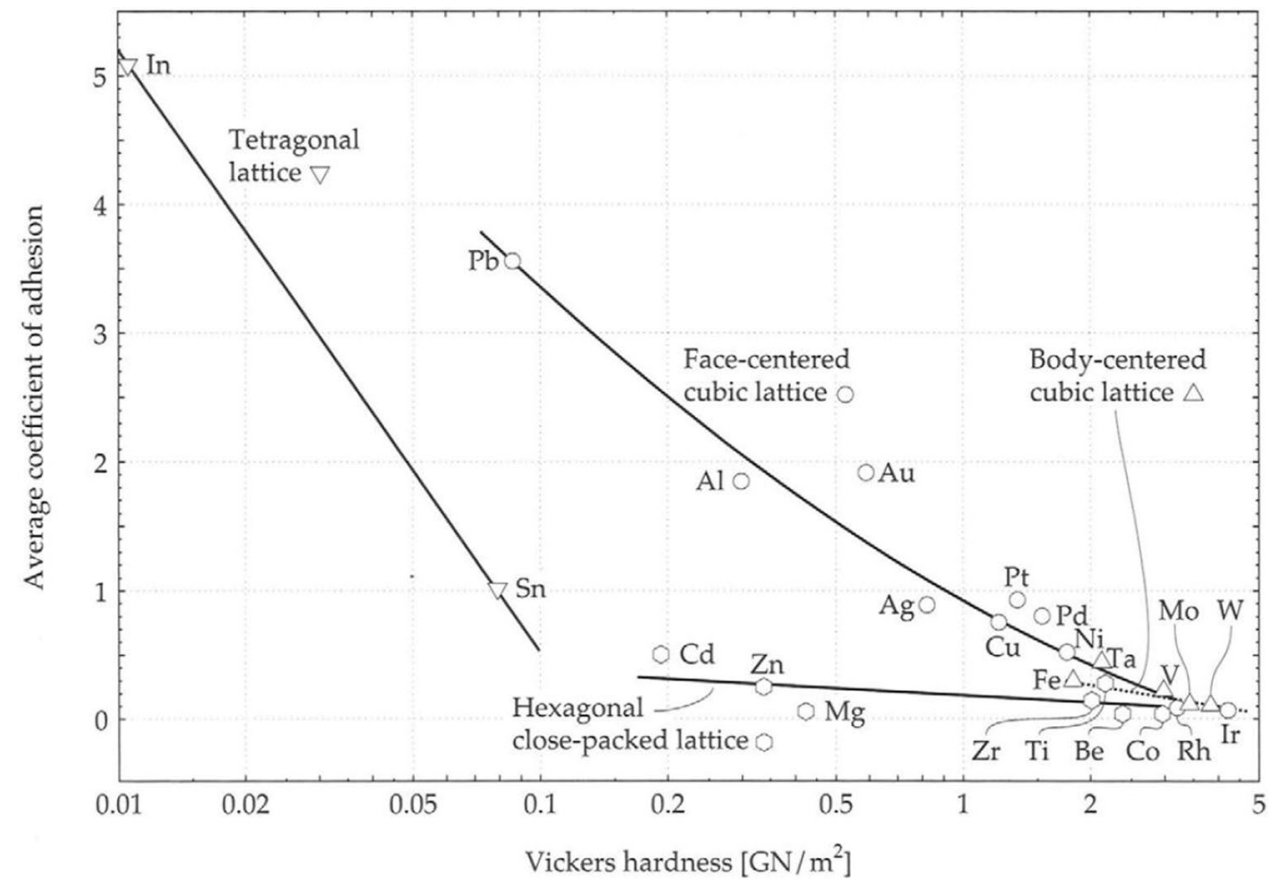

Potential (V vs. SHE)

$-0.5$

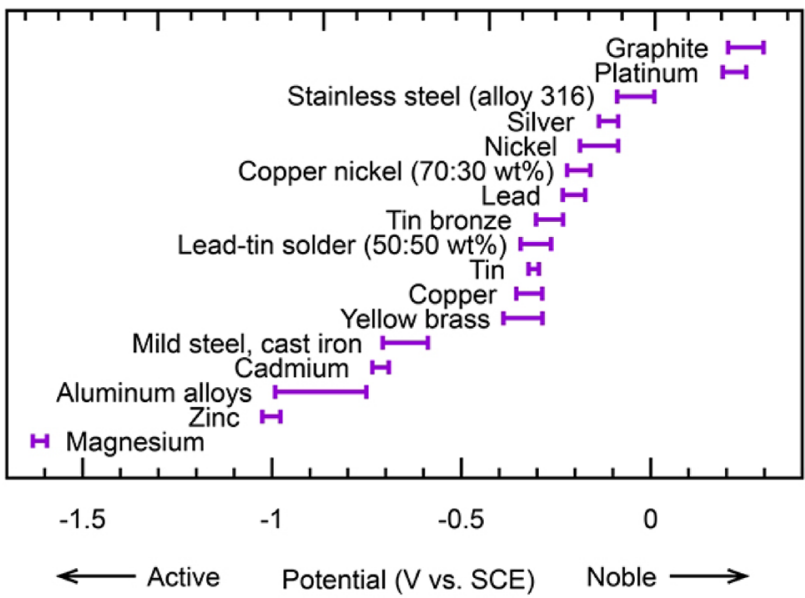

Fig. 19 Galvanic corrosion in seawater for common alloys [85]

steel. According to the authors, 304 stainless steel always acts as the cathode, with 2024 aluminium alloy acting as the anode under the tested conditions. Moreover, the potential difference between 304 stainless steel and Q235 mild steel was larger than that between Q235 mild steel and 2024 aluminium alloy. The authors conclude that the immersed media, either neutral, acid or alkaline solution, is highly influential with alkaline solution demonstrating the severest degradation. Therefore, the material pair selected for a forged multi-material gear must always consider the service environment to minimise degradation.

It is suggested that the use of spacer materials, that are less susceptible to the effects of galvanic corrosion depending on material pair, may be used to act as the interlayer material as presented in Sect. 5.4.3.

\subsection{Enhancing metallurgical bonds in multi-metal forging}

According to a review of the literature, the conditions of forging are beneficial for the formation of strong intermetallic bonds. In particular, the literature states that high temperature, pressure, relative material sliding and time in contact are positive promoters of bonding.

Time in contact is the most challenging variable to address in industry due to the competing requirements of minimised production time compared to maximising contact time to promote a diffusion bond [8]. Therefore, for practical applications, adjusting the variables of temperature, pressure and relative sliding are more acceptable by industry.

Elevated temperatures improve adhesion and diffusion of a joint as the increased temperature results in increased surface energy leading to an accelerated diffusion of electrons and atoms across a bond [57]. Moreover, elevated temperatures have the effect of increasing ductility of the material, 
thus aiding in the break-up of passivation layers. In particular, temperatures of at least 0.5 times melting temperature demonstrate clear diffusion [168]. There have been studies that have achieved successful welding at cold extrusion conditions reducing the intermetallic phase difficulties. Studies by Yoshida et al. [172] enabled the successful bonding of carbon steel and aluminium alloys despite their traditional difficulty in bonding. However, these were achieved with special conditions such as hydrostatic processing making it difficult to be applied in industry [60].

Elevated pressures are known to promote solid state welding [174], although the literature notes that this is typically limited to pressures of at least twice the material flow stress [146] Relative sliding between the two materials has been proven to be beneficial for a range of solid state welding processes, such as cold pressure welding. This is due to the large surface sliding disrupting surface oxide/passivation layers prior to static welding [173]. The use of relative sliding for bonding promotion has been exploited commercially in shear based welding processes such as friction stir welding [152], with studies showing that plastic deformation strains of approximately $40 \%$ are capable of disrupting oxide layers $[39,158]$.

According to Politis [120], the majority of literature studies involve maximising metal to metal contact for bonding promotion in order to disrupt the oxide layers, as shown in Table 1.

\subsubsection{Diffusion bonding in vacuum}

Diffusion bonding for industrial applications is traditionally performed in a vacuum or in an inert gas atmosphere to prevent the instantaneous formation of oxide films [137]. As discussed earlier, metal surfaces which have been cleaned from contaminants such as water and oil films rapidly develop an oxide layer which negatively affects the formation of a bond. However, the use of a vacuum is confined to small or simple geometries with applications to hot forging being impractical, due to the need to encompass a forging press, furnaces and associated handling equipment.

A compromise may be the use of an inert gas environment, such as argon, although even commercially pure argon consists of considerably more oxygen than a low vacuum of approximately $133 \mathrm{~Pa}[75]$.

\subsubsection{Macroscopic and microscopic plastic deformation}

During contact of two apparently flat surfaces, the microscopic surface roughness of each workpiece causes the contact to occur only at the asperities [22]. Plastic deformation processes involve high strains of the workpiece to disrupt surface oxide layers and subsequently expose the clean metal layers whilst effectively increasing the true contact area. This is achieved because metal oxide is significantly more brittle than the parent material, typically having a ductility of only a few percent of the pure metal [39] enabling the oxide to be fractured by the plastic deformation to form a high quality metal-metal bond [75, 148]. Such processes can cause a solid state atomic bond to occur between the two contacting bulk metals as shown in Fig. 20. This bond is further enhanced by forming at elevated temperatures over longer timescales [60].

In order to achieve an effective bond, a minimum plastic strain of approximately $40 \%$, for aluminium alloys, is required to break up the oxide layers $[39,158]$, with increasing strains up to $83 \%$ leading to improved bonds $[86,148]$. It should be noted that plastic deformation may be restricted by material ductility [142]. In addition, highly deformed material contains a large number of dislocations which improve the likelihood of bonding as the materials are more chemically active on the surface [22], as defects increase the energy in the material [24]. However, it should be noted that during macroscopic plastic deformation, the oxide layer itself is not eliminated or dissolved and is simply broken up to allow the parent metal to deform around it [148]. Therefore, this method alone will not result in an ideal metallic bond. Models of the oxide deformation and fragmentation process have been presented in the literature [28].

Microscopic plastic deformation operates on a similar principal in that the surface oxide layer is broken by deformation of the asperities at a microscopic level $[4,46]$. With this method, increased surface roughness improves the metallic contact, and hence the subsequent metallurgical bond $[50,128,139,147,151]$. Therefore, in combination
Table 1 Summary of methods to promote inter-metallic bonding

\begin{tabular}{lc}
\hline Method of bonding promotion & Reference \\
\hline $\begin{array}{l}\text { Conducting the process in a vacuum, with additional processes such as ion beam clean- } \\
\text { ing }\end{array}$ & {$[75,87,89,170]$} \\
Macroscopic and microscopic plastic deformation & {$[11,70,77,101$,} \\
& $144,145]$ \\
Applying interlayer & {$[47,80,137,159]$} \\
Mechanical cleaning and protective coating deposition & {$[27,34,136]$} \\
Active alloying elements & {$[75,94]$} \\
\hline
\end{tabular}


Fig. 20 Schematic of solid state welding evolution: a Plastic deformation of asperities, $\mathbf{b}$ Breakup of contaminant film and increase in true contact area of clean surfaces and $\mathbf{c}$ Weld formation [12]
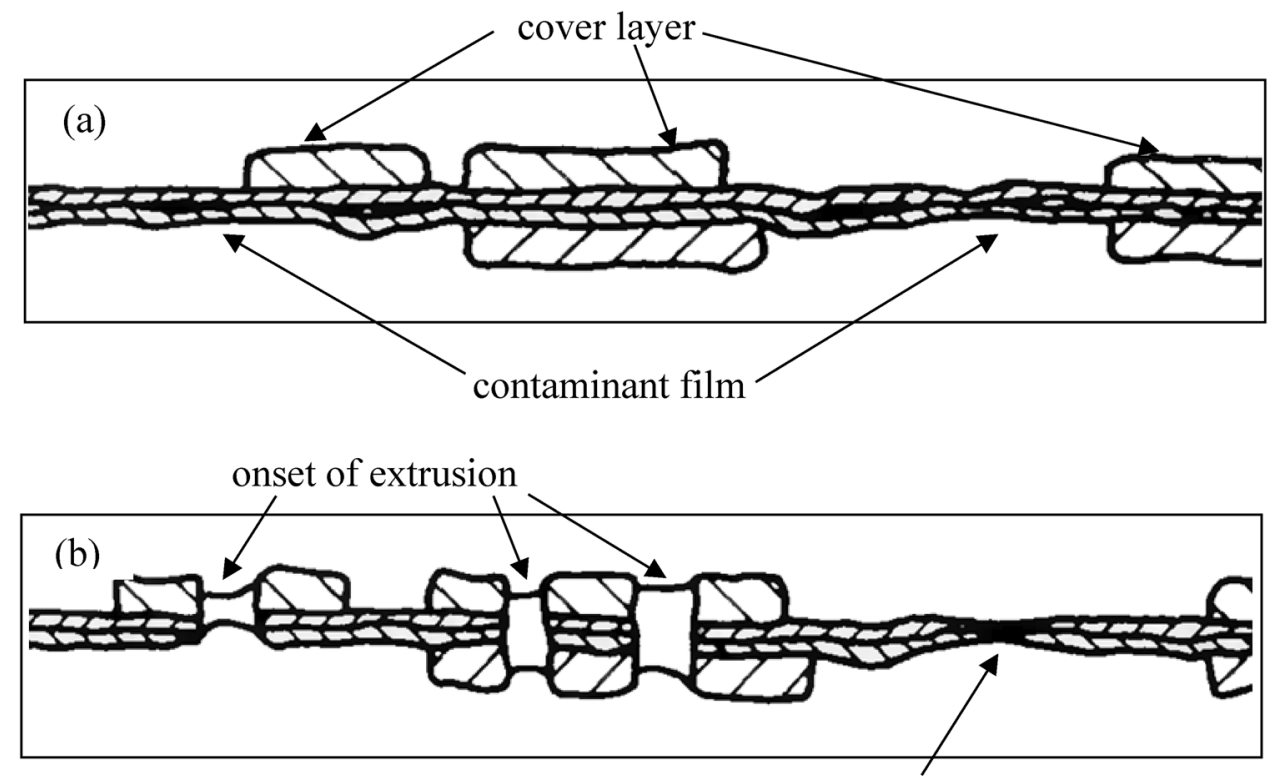

contaminant film

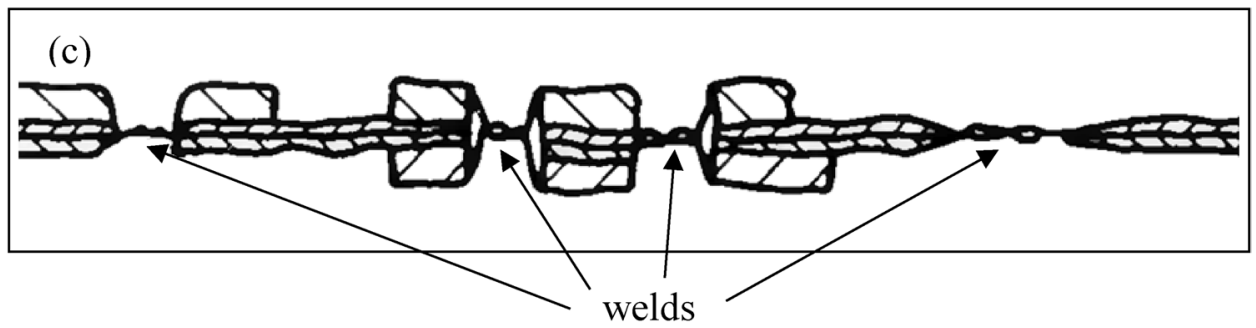

with macroscopic deformation, the use of high plastic strains and surface roughness are shown to promote intermetallic bonding.

Numerous mathematical models have been developed to describe the behaviour of bonding commencing with the surface roughness effects at first contact [139]. During first contact, subsequent compression results in the voids closing between the two materials. The diffusion bond that follows has been segmented into two parts: a diffusional controlled process, and a plasticity controlled process $[139,141]$. It is stated that the quality of the surface finish decides which process is more dominant, as for example, if the surface is relatively smooth, the process tends to be a diffusion controlled one. The tendency of one process compared to the other is the function of intersection radius [139]. The process of plasticity control operates by grain boundary sliding, grain rotation and movement [108], which is effective at breaking surface oxide layers [37, 165].

The material deformation with contaminant and passivation layer breakdown is a complex phenomenon. Bay [13] proposed a model to describe these phenomena as presented in Eq. 2.
$\frac{\sigma_{B}}{\sigma_{0}}=\left(1-\beta_{A}\right) \frac{p-p_{E}}{\sigma_{0}}+\beta \frac{Y-Y^{\prime}}{1-Y^{\prime}} \frac{p}{\sigma_{0}}$

where $\sigma_{B}$ is the bond strength, and $\sigma_{0}$ is the yield strength. The first term in the expression describes the fracturing of passivation layer, whereas the second term represents the fracturing of contaminant film [60]. $\beta_{A}$ represents the area fraction of the contaminant films, $p$ represents normal pressure, and $p_{E}$ represents the pressure at which extrusion of bulk material through the cracks in surface layers is initiated [12]. The expression $\frac{Y-Y^{\prime}}{1-Y^{\prime}}$ represents the true surface exposure for metals covered in contaminant films, where $Y$ is the surface expansion, and $Y^{\prime}$ is the threshold surface expansion to initiate cold welding for metals with only contaminant films [174]. While this model has been demonstrated to provide an effective representation of experimental results [174], it is limited to the cold welding of similar materials. The model has been extended to dissimilar materials by Zhang [173], however, to date there does not appear to be a model to represent high-temperature solid state welding of dissimilar metals in a forging process. 


\subsubsection{Applied interlayer materials}

As discussed previously, the insolubility of material pairs and galvanic corrosion may limit the quality of the interlayer bond. A promising solution to preventing both effects could be the use of a third interlayer material to promote bonding between dissimilar base metals [75]. This is particularly the case for the bonding of dissimilar metals with significant differences in thermal expansion coefficient [107], such as aluminium-steel joints [3] or materials with substantial differences in galvanic corrosion potential [85].

There are a range of interlayer materials and application methods proposed in the literature. The use of a foil interlayer has been demonstrated as a promising solution, where the deformation and splitting of the foil serve to effectively abrade the active surface and remove oxide films from the area of interest [106]. Politis [120] applied copper foil and silver foil to the interface of an aluminium and steel workpiece to promote bonding during forging trials. It was demonstrated that the application of a silver foil with texture pattern resulted in a bond failure load more than 10 times that of a simple copper foil. According to Zhang and Bay [174], the application of brittle Nickel or Chrome to the mating surfaces prior to solid state welding can promote the cracking of contaminant and passivation layers, thereby exposing clean bulk metal underneath for improved bonding.
A promising approach to an applied interlayer is the use of additive manufacturing technologies. Groche et al. [60] proposed the possibility of an additively manufactured outer layer which could be extended to the application of interlayer materials. Thusfar, multi-metal studies have focused on a solid inner material with an additively manufactured powder outer layer [20, 143]. However, it may be possible to additively manufacture a coating in a vacuum onto workpieces with high oxidising potential such as steels in order to also prevent oxidation during subsequent forging.

An alternative approach to the use of interlayer materials is the Transient Liquid Phase diffusion bonding [135]. In this process, a copper interlayer of thicknesses 3,7 , or $12.5 \mu \mathrm{m}$, is inserted between the two workpieces (A16082 and Al359) and interdiffusion between the applied interlayer and the base material pairs leads to the formation of a low melting point liquid phase (eutectic). This occurs at a constant bonding temperature [137]. As a result of the formed liquid phase, the surface oxide layer is broken up thus promoting metal-to-metal contact [137]. This liquid layer eventually solidifies isothermally due to continued diffusion at a constant bonding temperature. Improvements to the bond strengths achieved with this process were performed in subsequent studies [134, 135, 137]. Shirzadi [135], in the study of aluminium alloys with copper interlayers stated that a temperature differential between the upper and lower

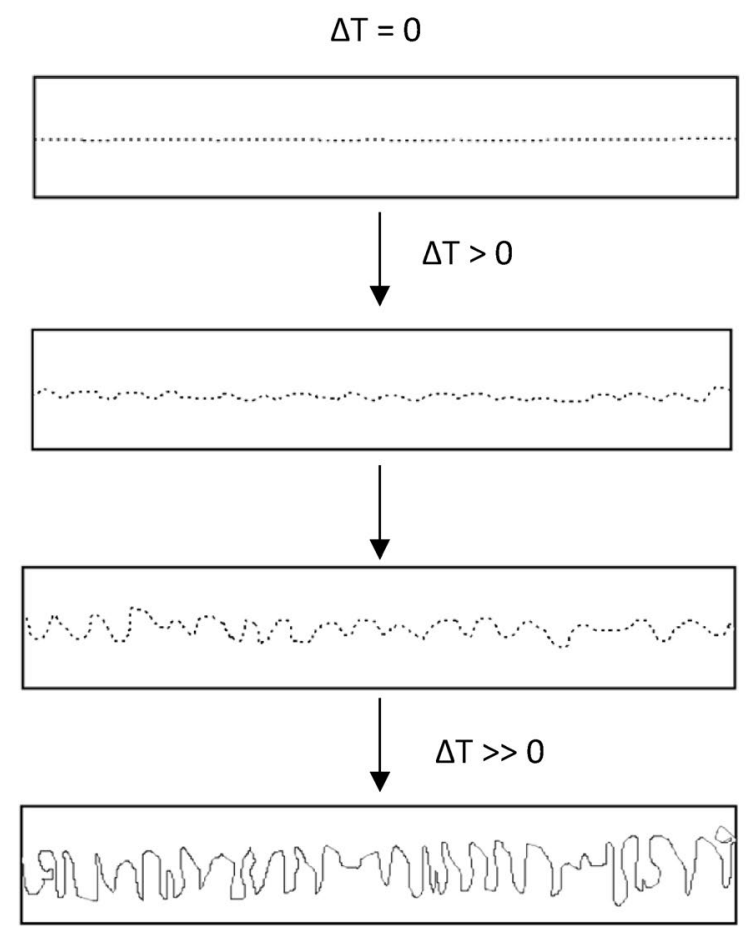

(a)
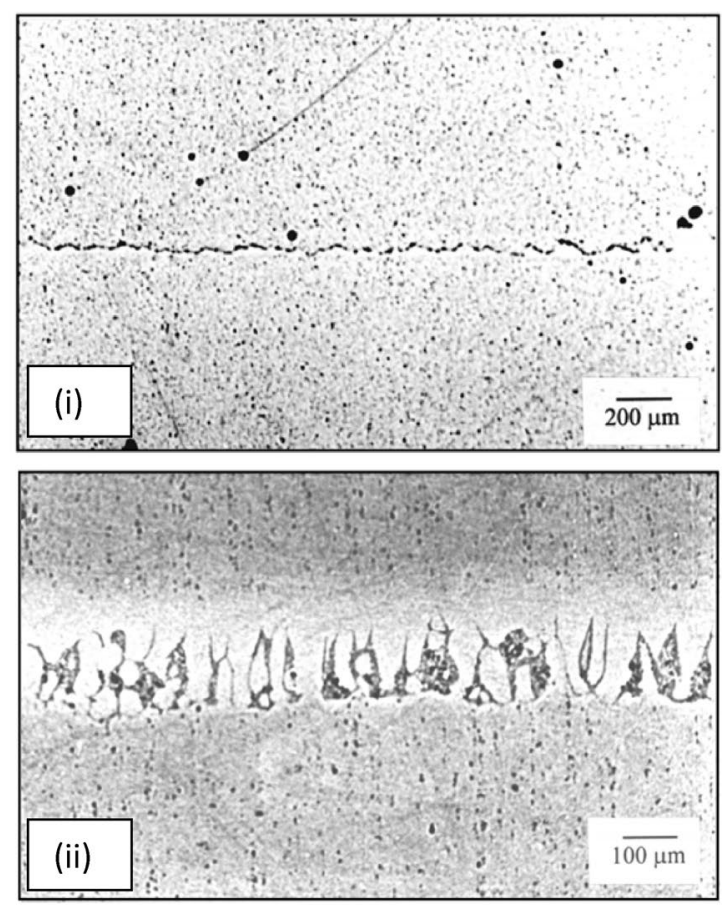

(b)

Fig. 21 Bond interface evolution with increasing temperature gradient $(\Delta \mathrm{T})$ between upper and lower workpiece $\mathbf{a}$ Schematic diagram and $\mathbf{b}$ Optical micrographs with (1) $20^{\circ} \mathrm{C} / \mathrm{cm}$ and (2) $70{ }^{\circ} \mathrm{C} / \mathrm{cm}$ temperature gradients [135] 
workpieces results in the formation of non-planar or horizontal, bond lines as shown in Fig. 21. It was found that the greater the temperature gradient $(\Delta \mathrm{T})$, varying from 20 to $70{ }^{\circ} \mathrm{C} / \mathrm{cm}$, the greater the sinusoidal variation of the interface, where, according to the authors, higher strength bonds with a lower degree of scatter were formed, with shear strengths in 6082 aluminium bonds approaching those of the investigated parent alloy.

From a review of the literature, it can be concluded that the conditions for hot forging, including deformation strain and temperature are suitable for the formation of effective bonds between multi-metal pairs. Form and force closed mechanical joints are formed due to the inherent nature of the forming process with the conditions being appropriate for the promotion of metallurgical bonding. For challenging materials such as aluminium and steel, suitable interlayer materials may be applied to further improve the bonding quality. The literature has shown that oxidation and passivation layers can be removed prior to and during forming to promote an effective intermetallic bond. However, the usage of interlayer materials in high-strain situations such as forging have seen limited investigation.

\section{Modelling of bi-metal gear forging processes}

The modelling of bi-metal forged components is challenging even at cold forging conditions due to the differing material properties, varying friction behaviour and large deformations. When incorporating hot forge properties, such as conduction, heat transfer coefficient, heat generation due to plastic deformation, pressure, and elastic deformation of tools, the processing power and simulation times required become inacceptable.

Politis et al. [118] modelled the cold forging of a bi-metal gear from model materials such as copper and lead. The material pairs were selected in order to avoid the need for elevated temperatures and enable lower forging loads in experimental work, thus removing a considerable number of variables from experimental and simulation work. The modelling of hot-forged bi-metal gears, from 8620 steel exterior and AA2014 aluminium interior materials, was performed by $\mathrm{Wu}$ et al. [169]. In this work, FE modelling of the process was conducted on Deform-3D. A comparison between the modelled and experimental results along cross sections of the bi-metal gear showed close comparison in the flow behaviour of the aluminium and steel materials. The simulation did include heat transfer parameters between the materials and tooling, however, the internal heat generation [23] with plastic deformation was not clearly stated with the study incorporating rigid rather than elastic tooling. It is expected that the inclusion of these variables is possible although with appreciable cost in computational efficiency.

The greatest challenge in bi-metal gear forging is the incorporation of the effect of the interlayer and intermetallic effects between the two base material pairs. Bambach et al. [7] proposed a finite element framework for a bond formed during plastic deformation processes with Khaledi et al. [78] proposing a mathematical model for bonding during large deformations. Finite element bond models have been applied to processes such as rolling [61], however, according to the authors' knowledge, there is no available study modelling the entire bi-metal gear hot forging process with intermetallic effects. Studies to date have focused specifically on the interlayer through the bonding of dissimilar materials. For example, Behrens et al. [18] characterised the joint zone via tensile tests for EnAW-6082 to $20 \mathrm{MnCr} 5$ and $\mathrm{C} 22$ to $41 \mathrm{Cr} 4$ joint pairs. In the study, the authors friction-welded two cylindrical samples along the axial direction of which dogbone tensile samples were extracted along the $0^{\circ}, 20^{\circ}$, and $30^{\circ}$ axis. However, in the forging of bi-metal gears, the varying geometry of the gear teeth, temperature variations and pressure profiles along the tooth root, flank, and tip, result in any experimental and numerical studies being focused on conditions found in specific regions of the bi-metal interface rather than the entire gear tooth profile.

To this end, Politis [120] proposed a simplified test rig and specimen geometries that were designed to replicate the interface conditions found in aluminium-steel gear forging along the tooth profile. The tests attempted to replicate bi-metal gear forging for the reviewed geometry in terms of the pressure, contact time, slip and temperature conditions at the tooth tip, flank and root simultaneously on a single conical workpiece, enabling subsequent tests of tensile and shear as shown in Fig. 22. The test rig also enabled the evaluation of interlayer materials to enhance bonding. As shown in the figure, the steel sample was cylindrical with a machined internal cone, with the aluminium sample having an inverted chamfer. The temperatures of $400{ }^{\circ} \mathrm{C}$ for the core, $950{ }^{\circ} \mathrm{C}$ for the ring, and $150{ }^{\circ} \mathrm{C}$ for the tooling were incorporated in the model similar to the gear forging trials. During forming, the radial movement of both materials was constrained, enabling the aluminium sample to flow into the cone of the steel sample, with a small contact band slipping on the steel surface towards the centre of the workpieces. As the load is increased, the locations marked as 'Average' and 'Last Contact' in Fig. 22a progressively roll out and contact onto the steel surface, with an increased strain and slip when compared with the 'First Contact' region. The overall effect is at the end of the deformation, there is a smooth variation in level of surface slip from the outside to the inside of the sample (excluding edge effects of the outermost diameter and central flat of the steel sample) which replicates the 


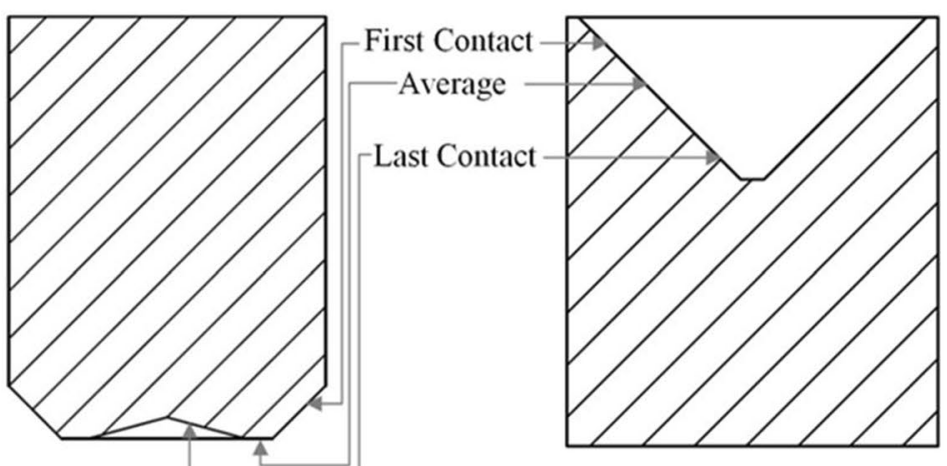

(a)

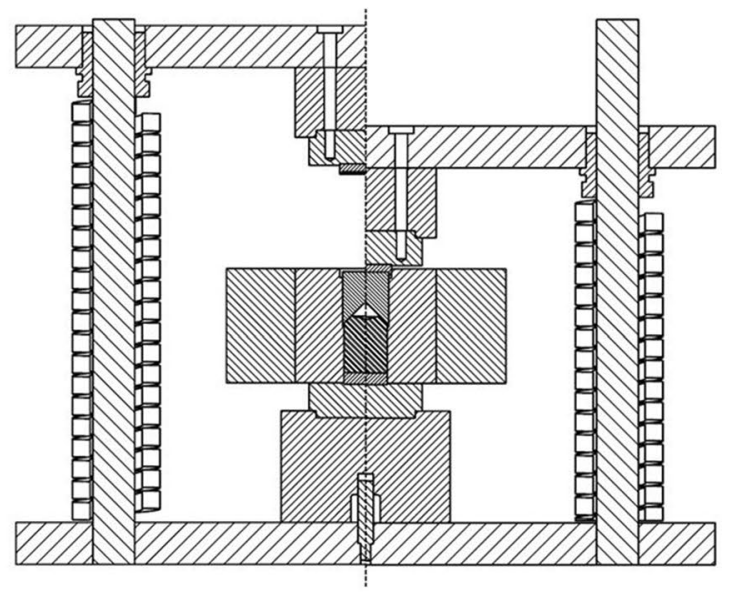

(c)

Fig. 22 Bi-metal forging interface conditions test-rig: a Aluminium sample, b Steel sample, c Cross-section of test rig [120]

strain and slip values found in analogous regions during the gear forging.

As can be seen from Fig. 23a and b, the highly complex nature of the interface such as the contact pressure and temperature are reasonably represented. The proposed test rig was subsequently utilised for the evaluation of bonding interlayer materials, which enabled the elimination of costly equipment required for full scale gear forging trials.

In addition to the modelling of the bi-metal forging processes, several studies have been conducted in the literature with the focus on the mechanical performance of the gears. Karpat et al. [74] evaluated the effect of outer ring thickness on the stiffness of the gear for an aluminium-steel and CFRP-steel gear. For an aluminium core, it was found that a decreasing thickness of the high strength ring reduces the gear tooth stiffness, with a stiffness reduction of up to $27.5 \%$ compared to a solid gear. However, with a modest ring thickness and CFRP core, it is possible to achieve similar stiffness with a solid steel gear at 38\% less weight. Yilmaz et al. [171] numerically investigated the static and dynamic behaviour of bimetallic spur gears using ANSYS. For the gear geometry selected, the authors found that ring thicknesses between $3.5-5 \mathrm{~mm}$ were optimum regarding weight reduction, and dynamic analysis showed that there is little difference between the solid and bimetallic gear designs. The variable that has a significant effect on the dynamic behaviour of the bimetallic spur gear is the addendum value. For example, when the addendum is increased by only $20 \%$ (from 1 to $1.2 \mathrm{~m}$ ), the maximum dynamic factor reduces by approximately $50 \%$. Moreover, the authors suggest that instead of modifying the stress profile within the gear by adjusting the steel ring thickness, it is possible to focus on adjusting gear variables such as tooth tip radius and pressure angle. In this way, bi-metallic gears can exhibit similar dynamic response and bending performance to solid steel gears whilst achieving up to $40 \%$ weight reduction. The effect on tooth stiffness for a range of steel ring thicknesses and a solid steel tooth are shown in Fig. 24.

As can be seen in Fig. 24, the tooth stiffness values decrease with decreasing ring thickness, which is expected due to the core material having a lower elastic modulus than the ring material. In the figure, the radius of $60 \mathrm{~mm}$ corresponds to the tooth tip whereas $53.25 \mathrm{~mm}$ corresponds to the base circle. In terms of thickness, the mean stiffness is reduced by $38 \%, 28 \%, 15 \%$ and $9 \%$ for ring thicknesses of $1,2,3.5$ and $5 \mathrm{~mm}$ respectively.

In addition to the evaluation of gear tooth stiffness, Politis et al. [119] evaluated the stress distribution during contact of bi-metal gears. In this study, the stress distribution at the location of contact, and tooth roots were modelled for aluminium-steel gears of uniform steel ring thicknesses of $1 \mathrm{~mm}, 2 \mathrm{~mm}, 4 \mathrm{~mm}$ and $6 \mathrm{~mm}$ and compared to a solid steel gear. In addition, the study incorporated the flow behaviour of the steel ring, including the thinning of the tooth flank determined during forging. In the study, it was found that the thinning occurring during forging had a significant effect on the compressive and tensile fillet stresses. For the evaluated gear geometry, a uniform steel ring thickness of $6 \mathrm{~mm}$ presented a stress distribution almost identical (within 4\%) to that of a solid steel tooth. However, when incorporating the true ring profile post forging, it was found that the stresses were $20 \%$ greater than in a solid steel gear (Fig. 25).

From these early works, it is found that lightweight bimetal gears can be designed to exhibit comparable performance to traditional single material steel gears. However, it should be noted that these studies were numerical in nature and thus further investigation including dynamic experimental testing is required. 
Fig. 23 Interface test rig modelling: a Contact pressure for gear forging simulation (at tooth root) vs. solid-state welding test simulation, b Steel surface temperature (final state) along interface [120]

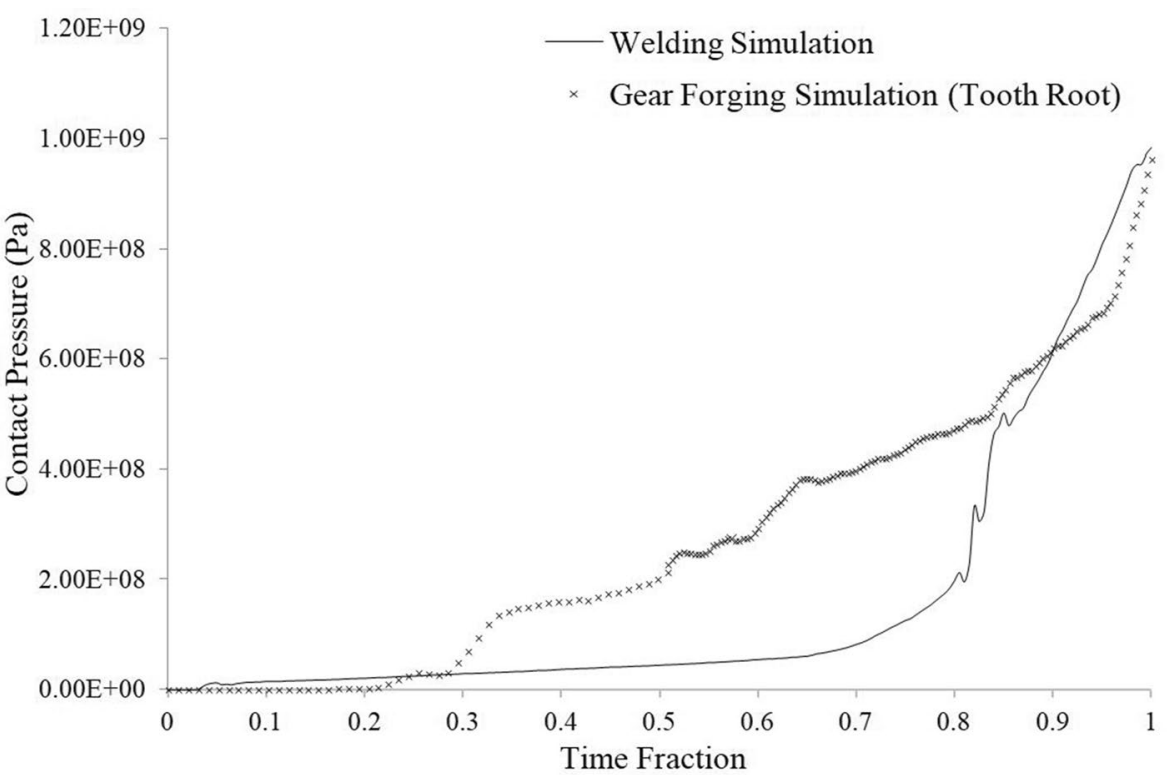

(a)

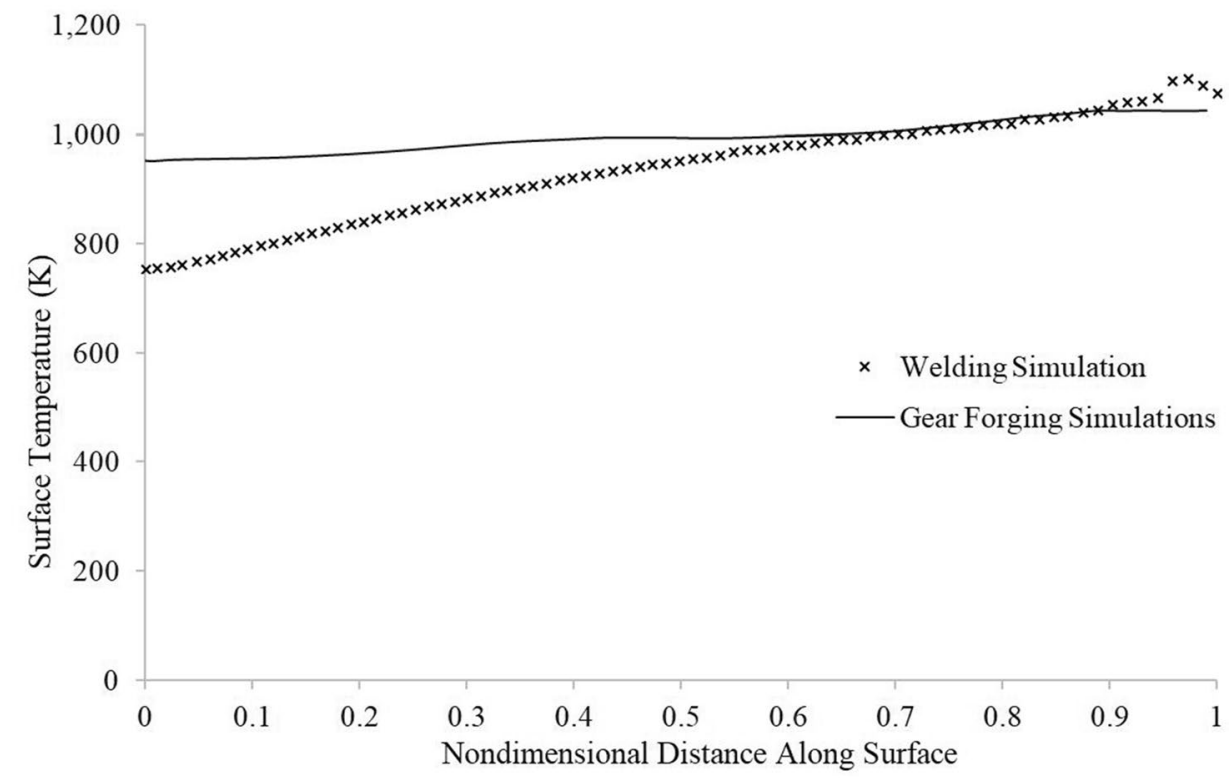

(b)

\section{Discussion}

The present paper provides an overview of the literature related to the development of forged lightweight multi-metal gears, ranging from the initial workpiece design, workpiece heating methods, multi-metal workpiece production, multimetal bonding and post forging analysis. A review of the literature has shown that each study has focused on a unique workpiece and gear geometry, thus resulting in a direct absolute comparison of the benefits of alternative methods being difficult, although it does provide indications as to the optimal processing route.
The production of effective multi-metal workpieces prior to forging is crucial for the success of forging. In the literature, this has been generally performed as either the production of a single workpiece combining two or more materials $[51,113,150]$, or the assembly of two or more metals into the die prior to forging $[118,169]$. For the production of a single multi-metal workpiece, significant processing prior to forging is required to optimise the workpiece integrity. For example, co-extruded inner core and outer sleeve materials require an extrusion tool arrangement which adds significant cost to small scale production lines [150]. Moreover, bi-metal casting [98], whilst being used for several decades 


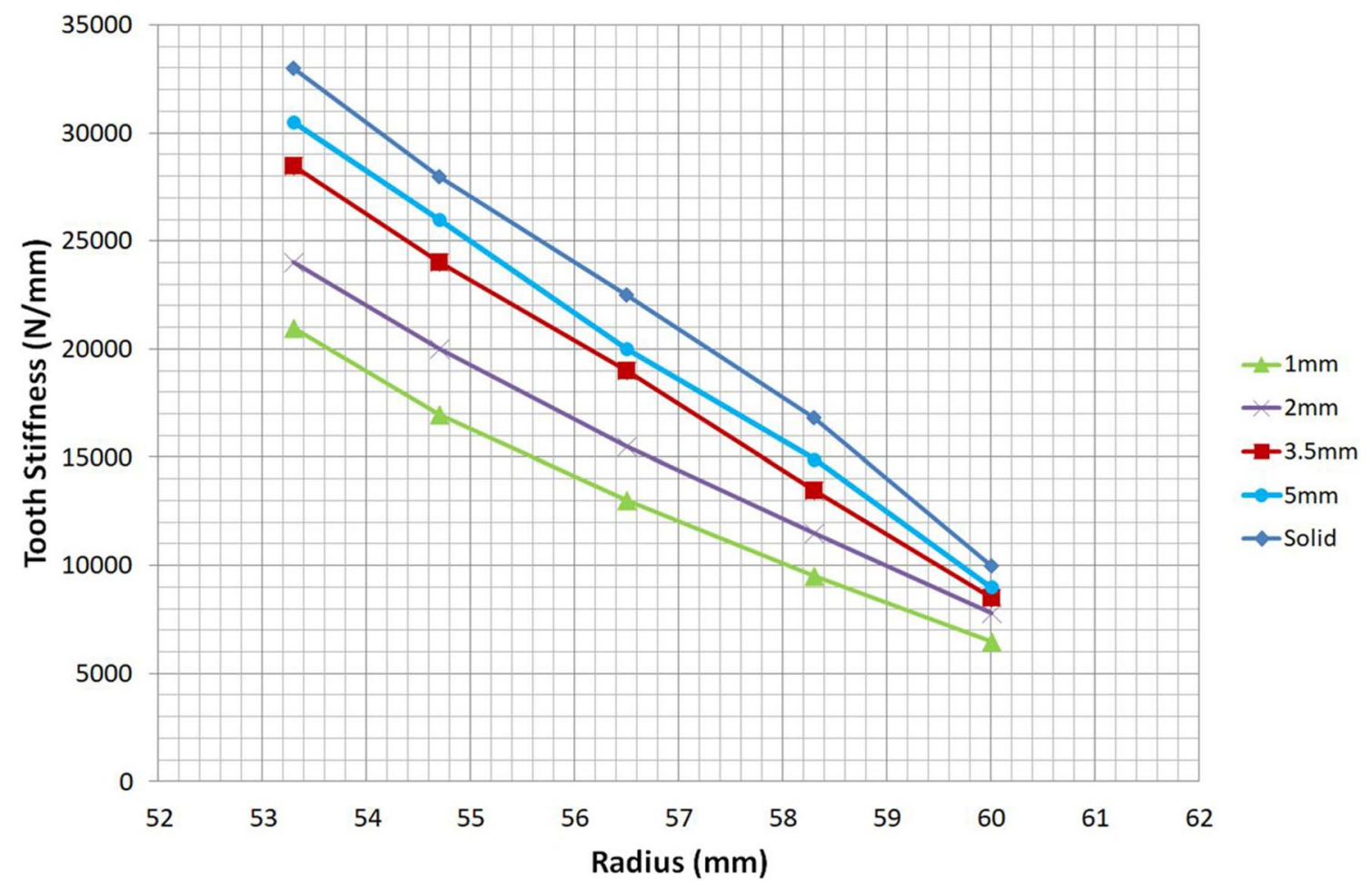

Fig. 24 Effect of steel ring thickness on tooth stiffness [171]

is limited to the selection of metals with similar thermal properties. Welding is a simple to use and widely available technology, which requires care to ensure air gaps between the two materials do not occur throughout the contact interface. The use of magnetic pulse welding technologies has shown that an air gap free surface could be achieved between two materials [55]. An alternative method to the pre-joining of dissimilar metals, which involves the telescopic assembly of an outer high strength ring, followed by a lightweight cylindrical core material has been investigated. Through this method, the metals are joined during the forging process as a result of the high temperatures and pressures experienced. Whilst the bond between the two metals was found to not be consistent, due to the variation in pressure across the tooth root, flank and tip interfaces, this method has avoided time intensive and costly operations prior to forging.

Forging of dissimilar metals at elevated temperatures is challenging as dissimilar metals may have excessive differences in thermal properties and flow behaviour including poor ductility, vastly different thermal expansion coefficients and melting temperatures. Aluminium-steel pairs have been investigated in the literature showing the ideal processing window of steel being $>900{ }^{\circ} \mathrm{C}$ and aluminium between $400-500{ }^{\circ} \mathrm{C}$, in order to avoid melting of the aluminium and to correlate the relative shrinkage due to differing thermal expansion coefficients. Behrens and Kosch [19] presented a processing window in order to correlate the differences in thermal behaviour and avoid the presence of an air gap after contraction of the materials post forging. Heating of preforms has been conducted in either individual furnaces each set to the required temperature of the metals, requiring the workpieces to be transported into the die and forged. Whilst a relatively simple method to perform, the transportation of workpieces from the furnace to the die can involve substantial temperature reductions of up to $50{ }^{\circ} \mathrm{C}$ resulting in a non-optimised forging [26]. Moreover, for gears requiring more than two metals, the use of several furnaces to heat individual workpieces becomes impractical. A promising solution is the use of induction heating coils to heat the workpiece whilst positioned within the die. Induction heating has been proven to heat telescopically assembled aluminium-steel pairs within $20 \mathrm{~s}$, and moreover, the presence of the air gap between the steel ring and aluminium core is favourable due to the induction heating only heating the outer steel blank with radiation heating increasing the temperature of the aluminium. Through appropriate selection of coil design and frequency, a single coil arrangement positioned on the outer perimeter of the steel ring can simultaneously heat aluminium and steel to their target temperatures $[19,56]$.

Experimental gear forging studies have demonstrated that mechanical bonding on the macro and micro scale 
Fig. 25 Stress distribution on the: a Compressive and b Tensile roots for bi-metal aluminium steel and solid steel gears [119]

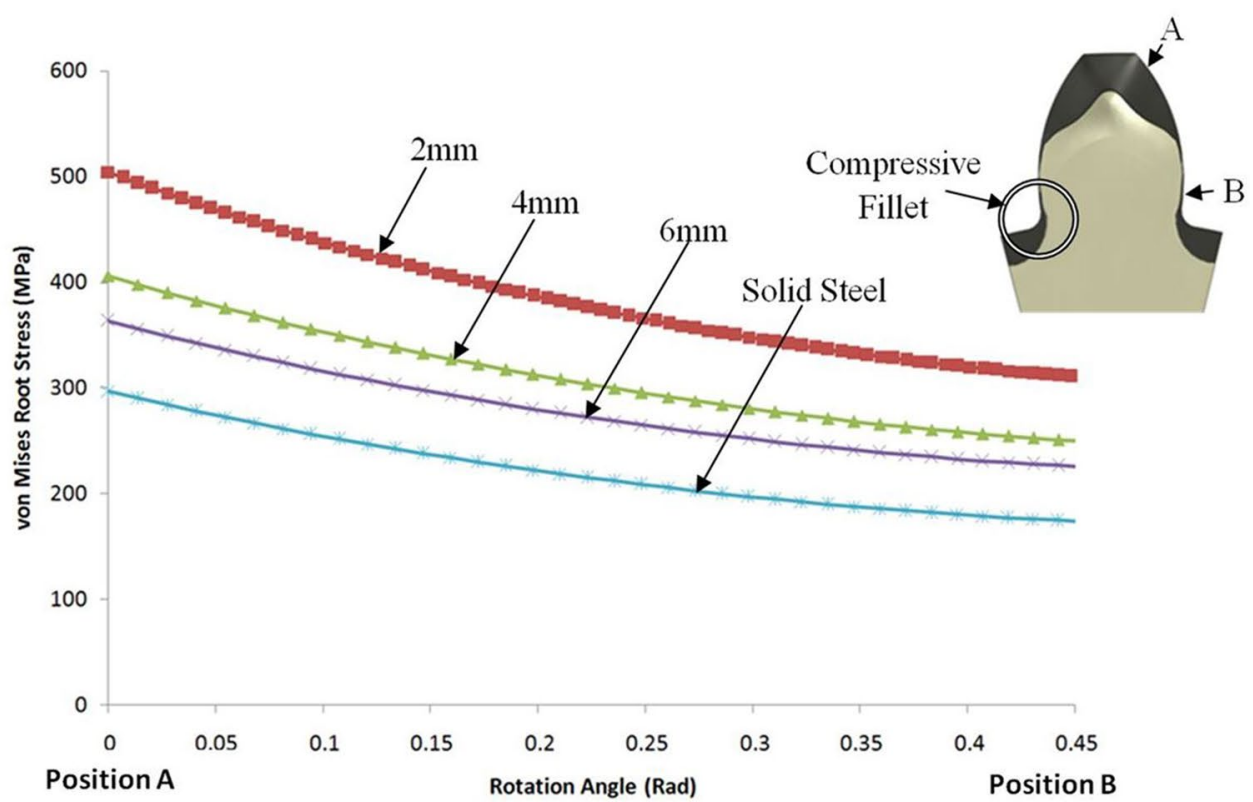

(a)

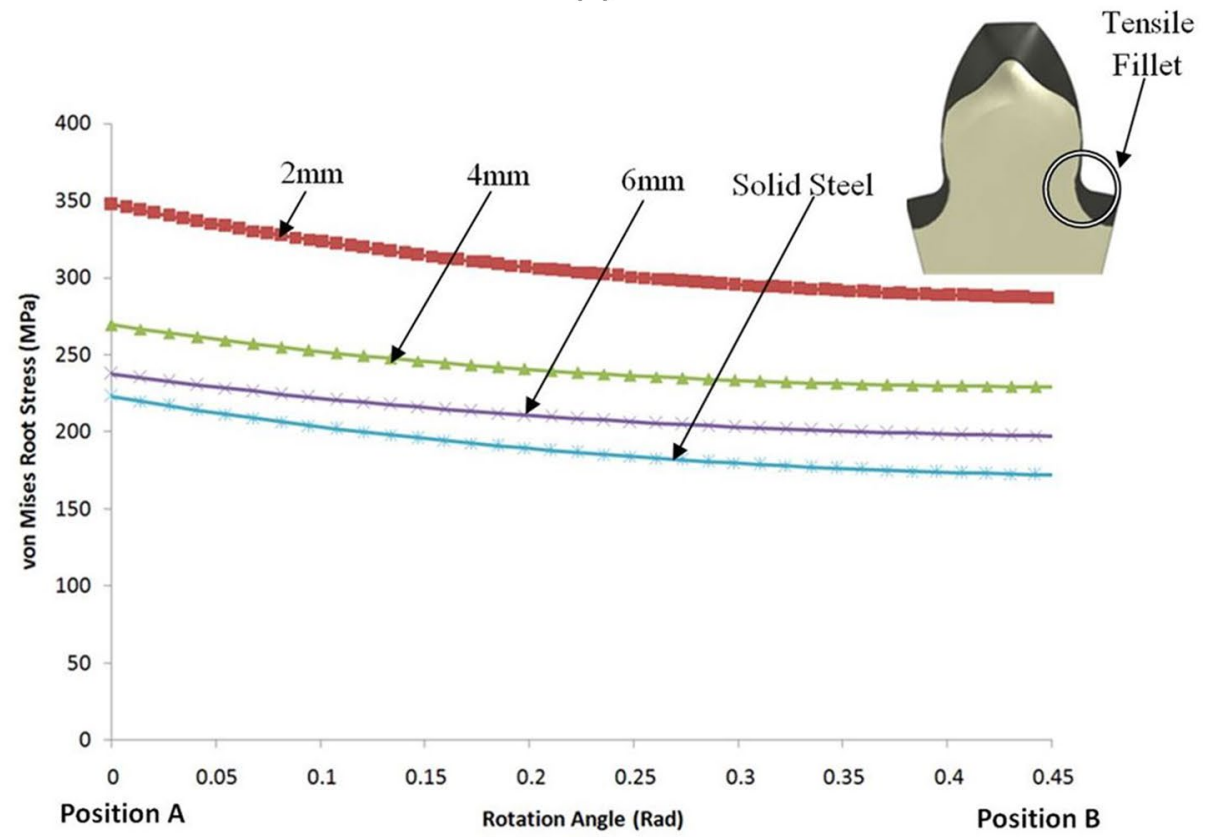

(b)

between dissimilar metals could be achieved during gear forging as a result of inherent forming of the gear teeth. The relative movement of an inner core material into the tooth profile restricts movement of the outer ring in both the rotational and axial direction, with axial restrictions forming as a result of friction between the punch and counterpunch against the workpiece. However, the greatest challenge to the integrity of a multi-metal gear is the metallurgical bond between the dissimilar pairs [4]. Forging conditions are favourable for diffusion bonding in forging as the pressure and temperature variables fulfil the requirements of such a bond. However, time under contact is an essential variable to the promotion of a strong metallurgical bond which is a competing requirement to the short production times required by industry [8]. Moreover, even thoroughly cleaned workpiece surfaces contain multiple contaminants of the order of several micrometres thick [75], with oxide quickly reforming post cleaning. It has been stated that an observable oxide layer can form on an aluminium workpiece within $15 \mathrm{~s}$ post cleaning at room temperature with times reducing at elevated temperature conditions [73]. 
Numerous methods to remove contaminant and passivation layers and promote diffusion bonding had been proposed in the literature. These include the use of a vacuum, macro and microscale deformation, the application of interlayer materials and protective coatings. The use of a vacuum, whilst effective, is impractical in a forging environment due to the size of the equipment involved [87]. For the application of a protective atmosphere, it may be possible to utilise an inert gas environment, such as argon gas, although it is recognised that there is significantly more oxygen present that could oxidise the workpiece surfaces. Macro and microscale deformation inherently occurs during the forging process. This is an effective diffusion bonding promoter as it disrupts the oxide layer that has a lower ductility than the parent materials, with strains of $40 \%$ being sufficient to break up this layer [158]. Whilst bonding is promoted, it should be noted that the oxide layer is not entirely dissolved or removed from the interface, but is simply broken up enabling base material to flow around it. Thus, these brittle areas of oxide may still potentially cause failure during long term operation of the gear. Interlayer materials have been proven to be highly effective at simultaneously encouraging bonding and also minimising galvanic corrosion [174] for materials of substantial corrosion potential such as aluminium-steel or magnesium-steel combinations. The application of interlayer materials has been performed as either a foil or an additively manufactured surface layer. According to the literature, nickel [66], copper [83] and even silver [10] are effective interlayers in bonding promotion.

Modelling of multi-metal forging is challenging due to the complexity of dissimilar properties and the interlayer surface. Finite element modelling of bi-metal forging processes has been conducted in the literature, however, the introduction of interlayer formation during such a forging process has not been performed according to the authors' knowledge. The study of interlayer surfaces is typically subject to dedicated studies with Behrens et al. [18] modelling such a surface through the tensile testing of samples extracted through the bonding of EnAW-6082 to $20 \mathrm{MnCr} 5$ and $\mathrm{C} 22$ to $41 \mathrm{Cr} 4$ material pairs. The limitation of such studies is that during gear forging, pressure and temperature conditions along the tooth root, flank and tip profiles vary significantly resulting in any evaluation focusing on only a portion of the multi-metal tooth interface. Politis [120] designed a simplified test rig to model the pressure and temperature conditions along the tooth interface with preliminary analysis showing a promising representation of the conditions found during bi-metal gear forging. The literature has also numerically evaluated the potential performance of bi-metal gears through the evaluation of tooth stiffness [74], dynamic characteristics [171] and internal tooth stresses [119]. It was found that for the evaluated geometries, bi-metallic gears exhibit similar bending performance to solid steel gears with a 40\% weight reduction, stiffness reduction between 9-38\% depending on outer steel ring thickness and tooth stresses between 4-20\% greater than solid steel. Therefore the literature concludes that substantial weight savings can be made with a minimised mechanical performance impact. However it should be stated that the evaluated studies were numerical in nature and experimental work is further needed to verify the multi-metal forged gear performance.

Modern modelling approaches such as the use of genetic algorithms and case based reasoning (CBR) systems are increasingly being applied for forging of single material components with promising potential to be extended to multi-metal production. Optimisation studies [138] have proven that knowledge based systems, once having defined appropriate boundary constraints, can rapidly converge to an optimised solution in a relatively short period of time. However, the user should take care in the selection of boundary condition constraints as optimisation systems may converge to local rather than global solutions. It is expected that such intelligent systems will enable rapid optimisation of preform design and processing parameter selection whilst avoiding the time intensive and repetitive unidirectional FE modelling and optimisation approach which is currently in use.

\section{Conclusions}

A review of the literature suggests that multi-metal gear forging is a promising solution to the reduction of gearbox assembly weight whilst maintaining performance. Numerous research works have focused on a range of material pairs including the achievement of cost reduction through the use of high strength steels at the tooth region with low carbon steel in the centre, or the reduction of weight through the replacement of low carbon steel with lightweight alternatives such as aluminium alloys. As research studies have focused on unique material pairs and geometries, it is difficult to directly compare all the methods to common benchmark values, although valuable lessons can be learnt regarding workpiece design, heating, forging and strengthening.

The co-extrusion of dissimilar metals is seen as the most rapid means of producing single workpiece bi-metal preforms, with the use of individual workpieces assembled in the die prior to forging as the lowest cost alternative due to the avoidance of manufacturing operations prior to forging. The advantage of pre-joining the multiple metals prior to forging is the more accurate control of the bond interface compared to bonding directly through forging. The effects of material compatibility are crucial to minimise the impact of galvanic corrosion and promote bonding, and interlayer materials are recommended to limit the adverse effects of these parameters. The thermal processing window is crucial to the success of a multi-metal gear as the use of 
inappropriate temperatures may lead to separation and the formation of an air gap due to differing thermal expansion coefficients, or result in cracking of the workpiece due to poor ductility. For aluminium-steel pairs it is recommended to heat steel to temperatures greater than $900{ }^{\circ} \mathrm{C}$ and aluminium between 400 to $500{ }^{\circ} \mathrm{C}$. This temperature selection also enables the control of thermal contraction post-forging to produce a robust gear. Induction heating to attain such temperature control is superior to the use of furnace heating as induction systems could be placed in close proximity to the die thus minimising thermal loss during workpiece transfer. Moreover, the literature has stated that a single coil design could heat both metals to their target temperatures thus avoiding the use of multiple furnaces. However, the selection of any method, or combination of methods, to produce a multi-metal forged gear is highly geometry and material dependent and therefore practical constraints mean there is no single processing route that is ideal for the manufacture of all multi-metal forged gears. Expert systems are expected to aid users in the optimisation of a gear forging, although these are still in the early stages of development, particularly for multi-metal gear forging operations, and show enormous potential to optimise all aspects of the manufacturing process. These systems would enable users to upload their geometry and material requirements, and through an evaluation of prior case studies stored in a database, provide a suitable avenue to the most efficient processing route for the forging of multi-metal gears.

Open Access This article is licensed under a Creative Commons Attribution 4.0 International License, which permits use, sharing, adaptation, distribution and reproduction in any medium or format, as long as you give appropriate credit to the original author(s) and the source, provide a link to the Creative Commons licence, and indicate if changes were made. The images or other third party material in this article are included in the article's Creative Commons licence, unless indicated otherwise in a credit line to the material. If material is not included in the article's Creative Commons licence and your intended use is not permitted by statutory regulation or exceeds the permitted use, you will need to obtain permission directly from the copyright holder. To view a copy of this licence, visit http://creativecommons.org/licenses/by/4.0/.

\section{References}

1. Abdel-Rahman ARO, Dean TA (1981) The quality of hot forged spur gear forms. Part I: Mechanical and metallurgical properties. Int J Mach Tool Design Res 21(2):109-127

2. Adam H (1997) Carbon fibre in automotive applications. Mater Des 18(4-6):349-355

3. Aleman B, Gutiérrez L, Urcola JJ (1993) Interface microstructures in diffusion bonding of titanium alloys to stainless and low alloy steels. Mater Sci Technol 9(8):633-641

4. Assadi H, Shirzadi AA, Wallach ER (2001) Transient liquid phase diffusion bonding under a temperature gradient: modelling of the interface morphology. Acta Mater 49(1):31-39
5. Awiszus B, Neugebauer R, Kittner K, Popp M (2009) Analyse des Quer-fließpressens als Analogieversuch zum Strangpressen unter besondererBerücksichtigung der Verbundbildung zwischen Aluminium und Magnesium. UTF Sci Online J 4:1-18

6. Bach FW, Duda T (2005) Moderne Beschichtungsverfahren. Wiley Verlag, Weinheim, pp 292-305 (ISBN 9783527309771)

7. Bambach M, Pietryga M, Mikloweit A, Hirt G (2014) A finite element framework for the evolution of bond strength in joining-byforming processes. J Mater Process Technol 214(10):2156-2168

8. Banerjee S, Mukhopadhyay P (2007) Phase transformations. Pergamon Mater Series 12:555-716

9. Barker TC, Williams R, Singer C, Holmyard EJ, Hall AR, Williams TI, Singer C, Holmyard EJ, Hall AR, Williams TI (1959) A history of technology. Oxford University Press, Oxford

10. Barrena MI, Matesanz L, Gómez de Salazar JM (2009) Al2O3/ Ti6Al4V diffusion bonding joints using Ag-Cu interlayer. Mater Charact 60(11):1263-1267

11. Bay N (2013) Cold welding part 2: process variants and applications. Metal Constr 19:486-490

12. Bay N (1983) Mechanisms producing metallic bonds in cold welding. Weld J 62:137-142

13. Bay, N. (1981) Cold pressure welding-a theoretical model for the bond strength. In: Proceed. Instn. Metall. Spring Res. Conf.: Joining of Metals Practice and Performance, pp 47-62. 10-12th April, Warwick, UK

14. Bedworth RE, Pilling NB (1923) The oxidation of metals at high temperatures. J Inst Metals 29(3):529-582

15. Behrens BA, Chugreev A, Matthias T, Nothdurft S, Hermsdorf J, Kaierle S, Ohrdes H, Twiefel J, Wallaschek J, Mildebrath M, Hassel T (2019) Investigation of the composite strength of hybrid steel-steel semi-finished products manufactured by laser beam welding and friction welding. 5th International Conference Recent Trends in Structural Materials. IOP Conf. Series: Materials Science and Engineering, 461, 012049

16. Behrens BA, Diefenbach J, Chugreeva A, Kahra C, Herbst S, Nurnberger F (2020) Tailored forming of hybrid bevel gears with integrated heat treatment. Procedia Manuf 47:301-308

17. Behrens BA, Goldstein R, Chugreeva A (2018a). Thermomechanical Processing for Creating Bi-Metal Bearing Bushings. Thermal Processing in Motion (TPIM) June 5-7, Spartansburg, South Carolina

18. Behrens BA, Chugreev A, Matthias T (2018) Characterisation of the joining zone of serially arranged hybrid semi-finished components. AIP Conf Proc 1960:040002

19. Behrens BA, Kosch KG (2011) Development of the heating and forming strategy in compound forging of hybrid steel-aluminum parts. Mat-wiss u Werkstofftech 42(11):973-978

20. Behrens BA, Kosch KG, Frischkorn C, Vahed N, Huskic A (2012) Compound forging of hybrid powder-solid-parts made of steel and aluminum. KEM 504-506:175-180

21. Bhushan B (2013) Introduction to tribology. . John Wiley \& Sons, New York

22. Bhushan B (2003) Adhesion and stiction: mechanisms, measurement techniques, and methods for reduction. J Vac Sci Technol B 21(6):2262-2296

23. Bragov A, Igumnov L, Konstantinov A, Lomunov A, Rusin E (2019) Effects of high strain rate and self-heating on plastic deformation of metal materials under fast compression loading. J Dynamic Behav Mater 5:309-319

24. Buckley DH (1981) Surface effects in adhesion, friction, wear, and lubrication, vol 5. Elsevier, Amsterdam

25. Buckley DH (1968) Influence of chemisorbed films of various gases on adhesion and friction of tungsten. J Appl Phys 39(9):4224-4233 
26. Buyco EH, Davis FE (1970) Specific heat of aluminum from zero to its melting temperature and beyond. J Chem Eng Data 15(4):518-523

27. Cao J, Liu J, Song X, Lin X, Feng J (2014) Diffusion bonding of $\mathrm{TiAl}$ intermetallic and Ti3AlC2 ceramic: interfacial microstructure and joining properties. Mater Des 56:115-121

28. Cantalejos NA, Cusminsky G (1972) Morphology of the interface of roll-bonded aluminum. J Inst Metals 100:20-23

29. Capuder T, Sprcic DM, Zoricic D, Pandzic H (2020) Review of challenges and assessment of electric vehicles integration policygoals: Integrated risk analysis approach. Electr Power Energy Syst 119:105894

30. Carle D, Blount G (1999) The suitability of aluminium as an alternative material for car bodies. Mater Des 20:267-272

31. Carter M (2011) Bladesmithing with murray carter: modern application of traditional techniques. Krause Publications, USA

32. Chavdar B, Goldstein R, Yang X, Butkovich J, Ferguson L (2015) Hot Hydroforging for Lightweighting. 5th International Conference on Distortion Engineering, 23-25 September, Bremen, Germany.

33. Cheepu MM, Haribabu S, Reddy YH, Muthupandi V (2015) Joining of AISI 1040 Steel to 6082-T6 aluminium alloy by friction welding. J Adv Mech Eng Sci 1:57-64

34. Chen C, Xie Y, Huang R, Deng S, Ren Z, Liao H (2018) On the role of oxide film's cleaning effect into the metallurgical bonding during cold spray. Mater Lett 210:199-202

35. Chen RY, Yeun WYD (2003) Review of the high-temperature oxidation of iron and carbon steels in air or oxygen. Oxid Met 59(5):433-468

36. Chen RY, Yuen WYD (2000) A study of the scale structure of hot-rolled steel strip by simulated coiling and cooling. Oxid Met 53(5):539-560

37. Chino Y, Kishihara R, Shimojima K, Hosokawa H, Yamada Y, Wen CE, Iwasaki H, Mabuchi M (2002) Superplasticity and cavitation of recycled AZ31 magnesium alloy fabricated by solid recycling process. Mater Trans 43(10):2437-2442

38. Chugreeva A, Mildebrath M, Diefenback J, Barroi A, Lammers M, Hermsdorf J, Hassel T, Overmeyer L, Behrens BA (2018) Manufacturing of high-performance bi-metal bevel gears by combined deposition welding and forging. Metals 8:898

39. Cline CL (1966) An analytical and experimental study of diffusion bonding. Welding J 45:481-489

40. Colestock HE (1971) Shrink fit assembly process. Patent No. U.S. 3,621,550, November 23

41. Crane CH, Lovell DT, Baginski WA, Olsen MG (1967) Diffusion welding of dissimilar metals. Weld J 46(1):S23

42. Cusumano MA, Kentaro N (1998) Thinking beyond Lean: How multi-project management is transforming product development at Toyota and other companies. The Free Press, New York

43. Ding Y, You G, Wen H, Li P, Tong X, Zhou Y (2019) Microstructure and mechanical properties of inertia friction welded joints between alloy steel $42 \mathrm{CrMo}$ and cast Ni-based superalloy K418. J Alloy Compd 803:176-184

44. Domblesky J, Kraft FF (2007) Metallographic evaluation of welded forging preforms. J Mater Process Technol 191(1):82-86

45. Donachie MJ (2000) Titanium: a technical guide. ASM international, Ohio

46. Dray AE (1985) Diffusion bonding of aluminium. Doctoral dissertation, University of Cambridge.

47. Duarte LI, Ramos AS, Vieira MF, Viana F, Vieira MT, Kocak M (2006) Solid-state diffusion bonding of gamma-TiAl alloys using Ti/Al thin films as interlayers. Intermetallics 14:1151-1156

48. Dybkov VI (1990) Interaction of 18Cr-10Ni stainless steel with liquid aluminium. J Mater Sci 25(8):3615-3633
49. Engelhardt M, Grittner N, Von Senden Genannt H, ReimcheW H, Bormann D, Bach FW (2012) Extrusion of hybrid sheet metals. J Mater Process Technol 212:1030-1038

50. Enjyo T, Ikeuchi K, Akikawa N (1978) Study of microscopic process of diffusion welding by electric-resistance measurement and transmission electron microscope. Trans JWRI 7(2):245-248

51. Förster W, Binotsch C, Awiszus B (2018) Process chain for the production of a bimetal component from $\mathrm{Mg}$ with a complete $\mathrm{Al}$ cladding. Metals 8:97

52. Freedonia, (2015) World Gears [Online]. http://www.freedoniag roup.com/industry-study/world-gears-3320.htm Accessed 24 July 2020

53. Garić S, Ivanović L, Stojanović B, Miladinović S, Milovanović V (2016) Numerical Analysis of Aluminum Composite Cylindrical Gears. Conference paper at 3rd International Scientific Conference COMETa.

54. Ghosh M, Bhanumurthy K, Kale GB, Krishnan J, Chatterjee S (2003) Diffusion bonding of titanium to 304 stainless steel. J Nucl Mater 322(2):235-241

55. Göbel G, Kaspar J, Herrmanndörfer T, Brenner B, Beyer E (2010) Insights into intermetallic phases on pulse welded dissimilar metal joints. In: 4th International Conference on High Speed Forming, 127-218.

56. Goldstein R, Behrens BA, Duran D (2017) Role of Thermal Processing in Tailored Forming Technology for Manufacturing Multi-Material Components. Conference Heat Treat, Columbus Ohio, USA

57. Gottstein G (2004) Physical foundations of materials science. Springer, Berlin

58. Grange HL, Hanink DK (1951) Method of forming composite aluminum-steel parts by casting aluminum onto steel and bonding thereto. Patent No. U.S. 2,544,670. March 13.

59. Groche P, Türk M (2011) Smart structures assembly through incremental forming. CIRP Ann Manuf Technol 60(1):21-24

60. Groche P, Wohletz S, Brenneis M, Pabst C, Resch F (2014) Joining by forming - a review on joint mechanisms, applications and future trends. J Mater Process Technol 214(10):1972-1994

61. Guenther S, Seitz J, Schwich G, Hirt G (2017) Investigation of a composite ring rolling process considering bonding behaviour in FEM and experiment. Procedia Eng 207:1236-1241

62. Haats J (1994) Verfahrensoptimierung beim Kaltpreßschweißen artverschiedenerkorrosionsbeständiger Metalle. VDI-Verl, Düsseldorf

63. Hack HP (2016) Module in materials science and materials engineering. Elsevier, Amsterdam

64. Handschuh RF, Roberts GD (2016) Hybrid gear. Patent No. U.S. 9,296,157. March 29.

65. Handschuh RF, Roberts GD, Sinnamon R, Stringer DB, Dykas BD, Kohlman LW (2012) Hybrid gear preliminary results-application of composites to dynamic mechanical components. NASA Technical Report 20120005332. NASA/TM-2012-217630, pp $1-18$

66. He P, Zhangand J, Zhou R (1999) Diffusion bonding technology of a titanium alloy to a stainless steel web with a $\mathrm{Ni}$ interlayer. Mater Charact 43:287-292

67. Hirschvogel Automotive Group (2020) Gear Lightweighting Idea. Available online at: https://www.hirschvogel.com/en/produ cts/transmission/gear-lightweighting-idea Accessed 31-7-20

68. Hofmann D (1990) Design and stress analysis of spur and helical gears, teaching pack on gear technology. British Gear Association, UK

69. Jaguar Land Rover (2017) Jaguar Land Rover, 2017. World Leaders in Aluminium [Online]. http://www.jaguarlandrover.com/gl/ en/innovation/world-leaders-in-aluminium/ Accessed 15 February 2017 
70. Jamaati R, Toroghinejad MR (2011) Cold roll bonding bond strengths: review. Mater Sci Technol 27(7):1101-1108

71. Jing S, Zhang H, Zhou J, Song G (2015) Optimum weight design of functionally graded material gears. Chin J Mech Eng 28(6):1186-1193

72. Joost WJ (2012) Reducing vehicle weight and improving US energy efficiency using integrated computational materials engineering. JOM J Mineral Metals Mater Soc 64(9):1032-1038

73. Kalpakjian S, Schmid SR (2006) Manufacturing, engineering and technology, 5th edn. Pearson Education Inc., New Jersey

74. Karpat F, Yilmaz TG, Dogan O, Kalay OC (2019) Stress and mesh stiffness evaluation of bimaterial spur gears. Proceedings of the ASME. International Mechanical Engineering Congress and Exposition, November 11-14, Salt Lake City, UT, USA.

75. Kazakov NF (1985) Diffusion bonding of Materials. Pergamon Press, Oxford (ISBN: 978-0-08-032550-7)

76. Keller D (1963) Adhesion between solid metals. Wear 6:353-365

77. Khaledi K, Rezaei S, Wulfinghoff S, Reese S (2019) Modeling of joining by plastic deformation using a bonding interface finite element. Int J Solids Struct 160:68-79

78. Khaledi K, Rezaei S, Wulfinghoff S, Reese S (2018) A microscale finite element model for joining of metals by large plastic deformations. CR Mec 346:743-755

79. Kitamura K, Hirota K, Ukai Y, Matsunaga K, Osakada K (2012) Cold joining of rotor shaft with flange by using plastic deformation. CIRP Ann Manuf Technol 61:275-278

80. Kriwall M, Stonis M, Bick T, Treutler K, Wesling V (2020) Dependence of the joint strength on different forming steps and geometry in hybrid compound forging of bulk aluminum parts and steel sheets. Procedia Manuf 47:356-361

81. Kroner A (2012) Hybrid forging is superior to joining technology. In: ALUMINIUM2012 Conference, Düsseldorf.

82. Krupp H (1972) Recent results in particle adhesion: UHV measurements, light-modulated adhesion and the effect of adsorbates. J Adhes 4:83-86

83. Kundu S, Ghosh M, Laik A, Bhanumurthy K, Kale GB, Chatterjee S (2005) Diffusion bonding of commercially pure titanium stainless steel using Copper interlayer. Mater Sci Eng, A 407:154-160

84. Lätzer M, Kleditzsch S, Leidich E, Awiszus B (2012) Analytical and numerical computation of knurled interference fits in comparison with experimental studies. IMEKO TC15 - Experimental Mechanics - Proceedings of the 11th Youth Symposium on Experimental Solid Mechanics, 112-117.

85. LaQue FL (1975) Marine corrosion: causes and prevention. Wiley, New York, p 179

86. Lee S, Wadsworth J, Sherby OD (1992) Impact properties of a laminated composite based on ultrahigh carbon steel and a NiSi-steel. J Eng Mater Technol 114(3):278-281

87. Lei Y, Hu SP, Yang TL, Song XG, Luo Y, Wang GD (2020) Vacuum diffusion bonding of high-entropy A10.85CoCrFeNi alloy to TiAl intermetallic. J Mater Process Technol 278:116455

88. Leiber R (2011) ALUMINUM: the ideal material for hybrid forgings, materials forum - intelligent lightweight construction. Hannover Messe, Hannover

89. Li G, Yang W, Jiang W, Guan F, Jiang H, Wu Y (2019) The role of vacuum degree in the bonding of $\mathrm{Al} / \mathrm{Mg}$ bimetal prepared by a compound casting process. J Mater Process Technol 265:112-121

90. Li P, Chen S, Dong H, Ji H, Li Y, Guo X, Yang G, Zhang X, Han $X$ (2020) Interfacial microstructure and mechanical properties of dissimilar aluminum/steel joint fabricated via refilled friction stir spot welding. J Manuf Process 49:385-396

91. Li S (2008) Centrifugal load and its effects on bending strength and contact strength of a high speed thin-walled spur gear with offset web. Mech Mach Theory 43(2):217-239
92. Liewald M, Felde A, Dörr F, Hajyheydari E, Henry R, Kannewurf M, Mletzko C, Riedmüller K, Schiemann T (2013) Identification of innovative process chains for cold forging. In: Liewald M (Eds) New Developments in Forging Technology. WerkstoffInformationsgesellschaft, Frankfurt, Germany, pp 1-32

93. Lueg-Althoff J, Bellmann J, Hahn M, Schulze S, Gies S, Tekkaya AE, Beyer E (2020) Joining dissimilar thin-walled tubes by Magnetic pulse welding. J Mater Process Technol 279:116562

94. Matsumae T, Kurashima Y, Takagi H (2018) Surface activated bonding of Ti/Au and Ti/Pt/Au films after vacuum annealing for MEMS packaging. Microelectron Eng 197:76-82

95. Matsumoto R, Hanami S, Ogura A, Yoshimura H, Osakada K (2008) New plasticjoining method using indentation of cold bar to hot forged part. CIRP Ann Manuf Technol 57:279-282

96. MCC International (2020) Bi-metal Casting. Available online at: http://www.millercentrifugal.com/index.php Accessed 29-6-20

97. Meißner R, Liewald M, Benkert T, Volk W (2017) Lightweight gearwheel design using separate gear ring and wheel body Part II: Different manufacturing concepts for replacing a full body gearwheel. 5th International Conference on Steels in Cars and Trucks. 18-22 June, Amsterdam, The Netherlands.

98. Miller WH (1974) Gear Blanks, Patent No. U.S. 3,847,557, November 12.

99. Misirli C, Cetintav I, Can Y (2016) Experimental and fem study of open die forging for bimetallic cylindrical parts produced using different materials". Int J Mod Manuf Technol 8(1):69-74

100. Mori K, Abe Y (2018) A review on mechanical joining of aluminium and high strength steel sheets by plastic deformation. Int J Lightwt Mater Manuf 1:1-11

101. Mori KI, Bay N, Fratini L, Micari F, Tekkaya AE (2013) Joining by plastic deformation. CIRP Ann Manuf Technol 62(2):673-694

102. Morton-Jones DH, Ellis JW (1986) Polymer products: design materials and manufacturing. . Chapman \& Hall, London

103. Msomi V, Mbana N (2020) Mechanical properties of friction stir welded AA1050-H14 and AA5083-H111 joint: sampling aspect. Metals 10:214

104. MTI Inc. (2020) Two pre-finished transmission gears welded using precision piloted tool. Available online at: https://www. mtiwelding.com/parts/?materials=steel-low-carbon-alloy-gearsteel Accessed 5-11-20

105. Muderrisoglu A, Murata M, Ahmetoglu MA, Kinzel G, Altan T (1996) Bending, flanging and hemming of aluminum sheet-an experimental study. J Mater Process Technol 59:10-17

106. Muktepavela F, Maniks J (2003) Mechanical properties of deformed interfaces in bimetallic joints. Solid State Phenom Trans Tech Publ 94:79-84

107. Nicholas MG, Crispin RM (1982) Diffusion bonding stainless steel to alumina using aluminium interlayers. J Mater Sci 17(11):3347-3360

108. Nieh TG, Wadsworth J, Sherby OD (2005) Superplasticity in metals and ceramics. Cambridge University Press, Cambridge

109. Oberle S (2006) Gearwheel and method for manufacturing a gearwheel. Patent No. U.S. 11/582,553. April 19.

110. Oda S, Mlyachika K, Sayama T (1986) Effects of rim and web thicknesses on bending fatigue strength of internal gear. Bull JSME 29(248):586-592

111. Oolderink R, Nizzoli E, Vandenbruaene H (2015) Composite gear blank. Patent No. U.S. 9,205,611. December 8.

112. Opalić, M., Vučković, K. and Kljajin, M. (2011) January. Effect of Web Arrangement on Thin-Rim Gear Tooth Contact Stress. In 15th International Research/Expert Conference-Trends in the Development of Machinery and Associated Technology, Prague, Czech Republic, 545-548.

113. Ossenkemper S, Dahnke C, Tekkaya AE (2019) Analytical and experimental bond strength investigation of cold forged composite shafts. J Mater Process Technol 264:190-199 
114. Owczarski W (1981) Application of diffusion welding. US Weld J 60(2):22-33

115. Pai V, Luk'yanov Y, Ku'zmin G, Yakovlev I (2006) Wave formation in a high-velocity symmetric impact of metal plates. Combust Explos ShockWaves 42:611-616

116. Poirier D, Grandmaison EW, Matovic MD, Barnes KR, Nelson BD (2006) High temperature oxidation of steel in an oxygenenriched low NOx furnace environment. J Int Flame Res Found 200602:1-27

117. Politis DJ, Lin J, Dean TA (2012) Investigation of Material Flow in Forging Bi-metal Components. Steel Research International. Proceedings of the 14th international Conference on Metal Forming. 231, 234.

118. Politis DJ, Lin J, Dean TA, Balint DS (2014) An investigation into the forging of Bi-metal gears. J Mater Process Technol 214(11):2248-2260

119. Politis DJ, Politis NJ, Lin J, Dean TA, Balint DS (2018) An analysis of the tooth stress distribution of forged bi-metallic gears. Proc IMechE Part C J Mech Eng Sci 232(1):124-139

120. Politis NJ (2017) Forging Lightweight Bimetal Gears. Doctoral Dissertation. Imperial College London, UK

121. Prakash B (1991) Metallurgy of iron and steel making and blacksmithy in ancient India. Indian J Hist Sci 26(4):351-371

122. Qiao J, Kou SQ, He DY, Yang SH (2008) Torque strength and influencing factors analysis for assembled camshaft by knurling joining. MSF 575:216-221

123. Rabinowicz E (1995) Adhesive wear. Friction and Wear of Materials, 2nd edn. Wiley, New York

124. Rampe JF (1990) Composite rotary drive member and method of its formation. Patent No. U.S. 4,946,427. August 7.

125. Rampe JF (1988) Rotatable drive member formed from injection molded plastics material with preform insert. Patent No. U.S. 4,722,722. February 2.

126. Raedt HW, Wilke F, Ernst CS (2015) Lightweight potential for a light commercial vehicle. Stahl Eisen 135(11):161

127. Reppe P, Keoleian G, Messick R, Costic M (1998) Life Cycle Assessment of a Transmission Case: Magnesium vs. Aluminum. SAE Technical Paper. 980470

128. Ricks RA, Mahon GJ, Parson NC, Heinrich T, Winkler PJ (1990) Proceedings of Conference on Diffusion Bonding, 2, Cranfield Institute of Technology, UK, 69.

129. Sampietro AC, Matthews KG (1965) Aluminum engine. Patent No. U.S. 3,173,407, March 16

130. Sayama T, Oda S, Umezawa K (1986) Study on welded structure gears: 11th report, optimum structure for thin-rimmed spur gear. Bull JSME 29(256):3582-3586

131. Schlemmer KL, Osman FH (2005) Differential heating forming of solid and bi-metallic hollow parts. J Mater Process Technol 162-163:564-569

132. Senjyo K, Toru Y (1971) Forging method for producing a hollow body. Patent No. U.S. 3,553,809. January 12.

133. Shi L, Yang X, Song Y, Liu D, Dong K, Shan D, Han EH (2019) Effect of corrosive media on galvanic corrosion of complicated tri-metallic couples of $2024 \mathrm{Al}$ alloy/Q235 mild steel/304 stainless steel. J Mater Sci Technol 35:1886-1893

134. Shirzadi AA (1998) Development and modelling of temperature gradient TLP bonding: a new method for joining advanced materials. Weld World 41(5):435-442

135. Shirzadi AA (1997) Diffusion Bonding Aluminium Alloys and Composites: New Approaches and Modelling. Doctoral dissertation. University of Cambridge, UK

136. Shirzadi AA, Wallach ER (2003) Bonding of metallic elements. Patent No. EP1084007, July 2.

137. Shirzadi AA, Wallach ER (1997) Temperature gradient transient liquid phase diffusion bonding: a new method for joining advanced materials. Sci Technol Weld Join 2(3):89-94
138. Siqueira R, Bibani M, Duran D, Mozgova I, Lachmayer R, Behrens BA (2019) An adapted case-based reasoning system for design and manufacturing of tailored forming multi-material components. Int J Interact Des Manuf 13:1175-1184

139. Somekawa H, Higashi K (2003) The optimal surface roughness condition on diffusion bonding. Mater Trans 44(8):1640-1643

140. Song G, Johannesson B, Hapugoda S, StJohn D (2004) Galvanic corrosion of magnesium alloy AZ91D in contact with an aluminium alloy, steel and zinc. Corros Sci 46:955-977

141. Speight MV, Beere W (1975) Vacancy potential and void growth on grain boundaries. Metal Sci 9(4):190-191

142. Stachowiak GW, Batchelor AW (2005) Engineering Tribology, 3rd edn. Elsevier Butterworth-Heinemann, Amsterdam

143. Szczepanik S, Nikiel P (2012) Some aspects of extrusion of two-layers PM materials. In: Kusiak, J. (Ed.), Metal Forming 2012, Proceedings of the 14th International Conference on Metal Forming. September 16-19, 2012. AGH Univ. of Science and Technology, Krakow, Poland, 475-478.

144. Schmidtchen M (2017) Multi-scale modelling of roll bonding and rolling of composite materials. Technische Universität Bergakademie Freiberg, Thesis

145. Schmidtchen M, Kawalla R (2010) Multiscale modeling of rolling processes and bond strength development for layered materials. Steel Res Int 81:230-233

146. Tabata T, Masaki S, Azekura K (1989) Bond criterion in cold pressure welding of aluminium. Mater Sci Technol 5(4):377-381

147. Takahashi Y, Tanimoto M (1995) Effect of surface asperity on interfacial contact process controlled by power law creepnumerical study of viscoplastic adhering process. J Eng Mater Technol 117(3):330-335

148. Tan YH, Lee SL, Wu HY (1996) Effects of beryllium on fatigue crack propagation of A357 alloys containing iron. Int J Fatigue 18(2):137-147

149. Taniguchi M, Shioiri H (2016) Ring gear fastening structure. Patent No. U.S. 9,297,449. March 29.

150. Tekkaya AE (2012) Recent developments in bulk metal forming. In: Ishikawa T, Yoshida Y, Hayakawa K, Wang Z (Eds.), Proceedings of the 45th ICFG Plenary Meeting (ICFG2012), 57-77.

151. Tensi HM, Wittmann M (1990) Proceedings of Conference on Diffusion Bonding, 2, Cranfield Institute of Technology, UK, 101

152. Thomas WM, Nicholas ED (1997) Friction stir welding for the transportation industries. Mater Des 18(4):269-273

153. Thurer SE, Uhe J, Golovko O, Bonk C, Bouguecha A, Klose C, Behrens BA, Maier HJ (2017) Co-extrusion of semi-finished aluminium-steel compounds. AIP Conf Proc 1896:140002

154. Townsend DP (1991) Dudley's gear handbook. Tata McGrawHill Education, New York

155. Toyota (2019) Toyota and Subaru Agree on New Business and Capital Alliance. Available online at: https://global.toyota/en/ newsroom/corporate/29916271.html Accessed 31/7/20

156. Tri-Tec Corporation (2020) Insert Molding. Available online at: https://www.triteccorp.com/products-services/insert-molding/ Accessed 31-7-20

157. UK Government (2020) Low-emission vehicles eligible for a plug-in grant. Available online at: https://www.gov.uk/plug-incar-van-grants Accessed 31/7/20

158. Urena A, Gómez de Salazar JM, Escalera MD (1995) Diffusion bonding of discontinuously reinforced $\mathrm{SiC} / \mathrm{Al}$ matrix composites: the role of interlayers. In Key Engineering Materials. Trans Tech Publ 104:523-540

159. Ustinov AI, Falchenko TuV, Ishchenko AY, Kharchenko GK, Melnichenko TV, Muraveynik AN (2008) Diffusion welding of $\gamma$-TiAl based alloys through nano-layered foil of Ti/Al system. Intermetallics 16:1043-1045 
160. Van Druten RM (2001) Transmission design of the zero inertia powertrain. Technische Universiteit Eindhoven, Netherlands

161. Verhoeven JD (2002) Genuine damascus steel: a type of banded microstructure in hypereutectoid steels. Steel Res 73(8):356-365

162. Volkswagen (2020) Range of Electric Cars. Available online at: https://www.volkswagen.co.uk/electric/ev-cars/new-electric-cars Accessed 31/7/20

163. Wadleigh AS (1993) Multi-metal composite gear/shaft. Patent No. U.S. 5,271,287. December 21.

164. Wang MY, Manoj R, Zhao W (2001) Gear rattle modelling and analysis for automotive manual transmissions. Proc Inst Mech Eng Part D J Automob Eng 215(2):241-258

165. Watanabe H, Moriwaki K, Mukai T, Ishikawa K, Kohzu M, Higashi K (2001) Consolidation of machined magnesium alloy chips by hot extrusion utilizing superplastic flow. J Mater Sci 36(20):5007-5011

166. Wells M (1965) Gears. Patent No. U.S. 3,200,665. August 17.

167. Won S, Seo B, Park JM, Kim HK, Song KH, Min SH, Ha TK, Park K (2018) Corrosion behaviors of friction welded dissimilar aluminum alloys. Mater Charact 144:652-660

168. Wu H, Lee S, Wang J (1998) Solid state bonding of iron-based alloys, steel-brass, and aluminum alloys. J Mater Process Technol 75:173-179
169. Wu P, Wang B, Lin J, Zuo B, Li Z, Zhou J (2017) Investigation on metal flow and forming load of bi-metal gear hot forging process. Int J Adv Manuf Technol 88:2835-2847

170. Yan H, Fan J, Han Y, Yao Q, Liu T, Lv Y, Zhang C (2019) Vacuum diffusion bonding $\mathrm{W}$ to $\mathrm{W}-\mathrm{Cu}$ composite: interfacial microstructure and mechanical properties. Vacuum 165:19-25

171. Yilmaz TG, Dogan O, Karpat F (2019) A comparative numerical study of forged bi-metal gears: bending strength and dynamic response. Mech Mach Theory 141:117-135

172. Yoshida Y, Matsubara T, Yasui K, Ishikawa T, Suganuma T (2010) Influence of processing conditions on joint strength in backward extrusion forged bonding.43rd ICFG Plenary Meeting 2010, Darmstadt, 192-198.

173. Zhang W (1994) Bond formation in cold welding of metals. Technical University of Denmark, Copenhagen

174. Zhang W, Bay N (1997) Cold welding-theoretical modeling of the weld formation. Weld J Includ Weld Res Suppl 76(10):477s

Publisher's Note Springer Nature remains neutral with regard to jurisdictional claims in published maps and institutional affiliations. 